\title{
Algunas consideraciones al tema de las mastopatias
}

Ponencia presentada al III Congreso Colombiano de Obstetricia y Ginecologia

Profesor Pedro Nel Cardona C., doctores Gustavo Isaza M., Gonzalo Vásquez, Fernando Cardona $A$.

De la Cátedra de Ginecologia de la Universidad de Antloquia. Hospital de San Vicente de Paúl de Medellín.

\section{INTRODUCCION}

La patologia de la glándula mamaria ha preocupado siempre a la humanidad. Su situación en la parte anterior al tórax, a corta distancia de la faz misma de la mujer, y siendo como es. uno de los distintivos principales de la feminidad, llega a ser. desde luego, un centro focal de exagerada importancia por lo cual es necesario conservarla y cuidarla con especial esmero para fines estéticos y funcionales.

Recientemente ha encontrado un papiro egipcio Edwin Smith, escrito siglos antes de Cristo y que,- a su vez, reproducia ctro de tres mil años antes de la éra cristiana, en el cual se hablaba ya de las enfermedades de la mama, seguramente porque cesde entonces era una de sus grandes preocupaciones $\left({ }^{*}\right)$.

Hoy, al cabo de 5.000 años, en plena éra atómica, tenemos similares preocupaciones, y con extrañeza y dolor. asistimos al desfile fatal de un gran número de enfermas, con cáncer del seno. sin que los conocimientos acumulados por la ciencia en el curso de los años sean valederos para detener la enfermedad.

El tema "mastopatias". es demasiado extenso e. inabordable para una ponencia. Citar tan solo unos capitulos. con recopilación literaria de lo escrito por los autores en libros y revistas, nos pareció muy humilde tarea. Por otra parte. la organización del trabajo en el Hospital de San Vicente donde los ponentes oci-

(*) Kharadly M. Symposium. Tomo IV, número 3 . 
pan posiciones en la Cátedra de Clínica Ginecológica, nos privó cie la oportunidad que ambicionábamos de estudiar y seguir el curso completo del tratamiento en las pacientes con enfermedades de la mama, ya que esta patología está consignada al servicio de cirugía general.

Estando ya las cosas en este terreno, resolvimos afrontar el problema con el estudio de los 1.181 casos de mastopatías vistas En el Instituto de Anatomía Patológica de la Facultad de Medicina, de la Universidad de Antioquia que dirige el profesor Alfredo Correa Henao, con éxito laudable, tratando de analizar los estudios histológicos practicados en los trece años de vida que lleva la institución. Al efecto, dividimos el material en 3 secciones principales, la primera consagrada al estudio de las lesiones inflamatorias agudas y crónicas, que alcanzaron, como quien dice al honor, de suministrar piezas operatorias tributarias del Instituto: sobra decir que nuestra reseña sobre el particular es relativamente pobre en material, porque la gran mayoria de los casos, como es obvio, no son sometidos ni a biopsia ni menos aŭn a extirpaciones mutilantes.

En segundo lugar, colocamos la patologia correspondiente a tumores benignos de la mama; y por último, hicimos un estudio, un poco más detallado, sobre el cáncer, por considerarlo de la mayor importancia, ciñéndonos en todo a los hallazgos antomopatológicos mencionados.

No se estudia el aspecto propiamente dicho de los casos analizados, tales como indicaciones operatorias, resultados inmediatos del tratamiento, mortalidad en el curso de los cinco primeros años, curaciones de cinco y más años, etc., etc., por las razones antes anotadas. No obstante, traemos a discución algunos puntos en relación con el diagnóstico y tratamiento del cáncer del seno, que esperamos merezcan la atención debida para puntualizar y definir tan importante cuestión.

En resumen, el trabajo que aportamos al Congreso es un estudio sintético de 1.181 casos-de mastopatías, mirados desde un solo puntộ de vista, clasificados de acuerdo con los hallazgos histológicos y complementạdos con algunas consideraciones de orden clínico que pueden ser interesantes en la discusión que seguramente provocará la lectura y estudio del trabajo.

\section{Mastitis aguda}

Las mastitis agudas se presentan con más frecuencia en la mama lactante, siendo su agente etiológico en la mayoría de los 
casos el Estabilococcus Aureus y su puerta de entrada, las grietas y erosiones del pezón.

El total de especimenes llegados al laboratorio en el transcurso de trece años fue de 7 , lo que nos da un porcentaje en las 1.181 mamas estudiadas de $0,5 \%$. Esta cifra tan baja, bien corresponde a la éra de antibióticos en que vivimos (cuadro número 1).

\section{MASTITIS AGUDA}

Total: 7. Promedio por año: 0.5 .

Porcentaje de las 1.185 mamas estudiadas: $0.5 \%$.

Presunción clínica de acuerdo: 0 .

Se pensó en carcinoma: 1.

Se pensó.en sarcoma: 1.

Biopsia o resección parcial: 5 .

Biopsia por congelación: 0 .

Mastectomía simple: 2 .

\section{CUADRO NUMERO 1}

La edad osciló entre 34 y 55 años, siendo más frecuente a los 50. La evolución va desde los 15 días hasta los 2 años, mostránconos que no todas las mastitis anatomopatológicamente agudas tienen su evolución semejante y que bien pueden presentarse como exacerbación de un proceso subagudo o crónico como pudimos comprobar en 4 de las 6 historias.

Los datos clínicos en orden de frecuencia fueron: tumor de crecimiento continuo, supuración, dolor y zona congestiva. Una tumoración era indolora. Su diagnóstico no siempre es fácil como a primera vista parece, cn nuestra corta serie la presunción clínica estuvo de acuerdo en 0 casos, y se pensó en adeno-carcinoma del seno en 1 y en linfosarcoma en 1.

Se hizo biopsia o resección parcial en 5 , biopsia por congelación en 0 , y mastectomía simple en 2.

\section{Mastitis subaguda}

El total de mamas estudiadas con diagnóstico anatomopatologico de mastitis subagudas en los 13 años, fue de 10; 1o que nos da un promedio por año de $0.7 \mathrm{y}$ un porcentaje en $1.181 \mathrm{ma-}$ mas examinadas de $0.08 \%$ (cuadro número 2 ). 


\section{MASTITIS SUBAGUDA}

Total: 10. Promedio por año: 0.7 .

Porcentaje de las 1.181 mamas estudiadas: $0.8 \%$.

Presunción clínica de acuerdo: 2.

Se pensó en carcinoma: 3 .

Biopsia o resección parcial: 8 .

Biopsia por congelación: 0 .

Mastectomía simple: 1 .

Mastectomía radical: 1 .

\section{CUADRO NUMERO 2}

Respecto a su evolución podemos clasificarlas en dos grupos: el primero, con historia menor de 6 meses que nos indica que son procesos inflamatorios de poca virulencia o de gran defensa orgánica; el segundo, con antecedentes de más de un año que nos muestra claramente procesos que ya en estado crónico se exacerbaron.

Los datos clínicos en orden de frecuencia fueron: tumor duro no mayor de 5 centímetros de diámetro, evolución rápida, dolor $(50 \%)$, adherencia a los planos vecinos $(50 \%)$, piel de naranja y fistulización.

$\mathrm{Su}$ diagnóstico antes del estudio anatomo-patológico solo se hizo en 2 casos, se pensó en adenocarcinoma en 3 , debido sin duda a la dureza, fijación y piel de naranja, síntomas éstos que no son exclusivos, ni mucho menos patognomónicos de las lesiones malignas.

Se hizo biopsia o resección parcial en 8 , biopsia por congelación en 0 , mastectomia simple en 1 , y mastectomía radical en 1.

\section{Mastitis crónica}

Se estudiaron un total de 55 especímenes con un promedio de 4,2 por año, y un porcentaje en el total de mamas de $4,5 \%$ (cuadro número 3 ). 


\section{MASTITIS CRONICA}

Total: 55. Promedio por año: 4.2.

Porcentaje de las 1.181 mamas estudiadas: 4.5.

Presunción clínica de acuerdo: 8.

Se pensó en carcinoma: 10.

Biopsia o resección parcial: 45 ....

Biopsia por congelación: 2.

Mastectomía simple: 7 .

Mastectomía bilateral: 1 .

Mastectomía radical: 2 .

\section{CUADRO NUMERO 3}

La edad de las pacientes osciló entre los 18 y 70 años, siendo más frecuentes de los 30 a los 50.

La evolución en nuestra serie es de un mes a doce años, la mayoria corresponden al primer año, y solo casos aislados terían historia de más de dos años.

Los datos clínicos más significativos en orden de frecuencia fueron: tumor duro de 1 a 8 centímetros de diámetro, siendo su tamaño más frecuente el de 2 , dolor espontáneo que se acentúa a la palpación, adherencia a los planos vecinos, ulceración, fistulización, adenopatías, retracción del pezón y secreción purulenta por el mismo.

La presunción clínica fue correcta en 8 , de ellas 6 tenían historia de supuración por el pezón y 2 procesos crónicos que habían cedido clínicamente a antibióticos en época anterior.

Se pensó en carcinoma en 10 de las 55,2 de ellas con biopsia previa de adenocarcinoma que al hacer la mastectomía radical y el estudio de la pieza solo se encontró mastitis crónica y ganglios normales, es decir, eran adenocarcinomas que aún no habian dado metástasis y que fueron sacados con la biopsia.

Se hizo biopsia o resección parcial en 45 , biopsia por congelación en 2, mastectomía simple en 7 , bilateral en 1 , y radical en los 2 casos con biopsia de adenocarcinoma.

\section{Mastitis con abseeso}

Se estudiaron un total de 39 especimenes con un promedio por año de 3 y un porcentaje en lo refente a mamas de $3,3 \%$ (cuadro número 4). 


\section{MASTITIS CON ABSCESO}

Total: 39. Promedio por año: 3 .

Porcentaje de las 1.181 mamas estudiadas: $3.3 \%$.

Presunción clinica de acuerdo: 10.

Se pensó en carcinoma: 9.

Biopsia o resección parcial: 24 .

Biopsia por congelación: 0 .

Mastectomía simple: 10.

Mastectomía radical: 5 .

\section{CUADRO NUMERO 4}

La edad osciló entre los 22 y 68 años, siendo más frecuente en la tercera década y alrededor de los 40 .

Su evolución abarca de los 15 días a los 5 años, encontrándose la mayoría con historia no mayor de 2 años.

Los datos clínicos en orden de frecuencia fueron: tumor duro fluctuante. de 2 a 15 centimetros de diámetro, dolor, fistulización, adherencias a los planos profundos y superficiales, pezón retraído y adenopatia axilar.

La presunción clínica estuvo de acuerdo en 10; 6 de ellas diagnosticadas al extraer material purulento en el acto quirúrgico de la biopsia o resección. Se pensó en carcinoma en 9 .

Se hizo biopsia o resección parcial en 24, biopsia con congelación en 0 , mastectomía simple en 10 , y mastectomía radical en 5 .

\section{Mastitis compatib'e con T. B. C.}

La mastitis tuberculosa es poco frecuente, Harrington encontró 1 caso por cada 200 de carcinoma, Geschickter 4 por cada 200 y nosotros 1 por cada 200.

En las 1.181 mamas estudiadas (cuadro número 5), encontramos lesión anatomo-patológica compatible con T. B. C. en 2 , lc que nos da un porcentaje de $0.1 \%$, y un promedio por año de 0.15 .

No nos fue posible hacer coloración especial para B. K. y es ésta la razón por la cual nos referimos a estos dos casos como lesión anatomo-patológica "compatible". 
MASTITIS COMPATIBLE CON T. B. C.

Total: 2. Promedio por año: 0.15 .

Porcentaje de las 1.181 mamas estudiadas: $0.1 \%$.

Presunción clinica de acuerdo: 0 .

Se pensó en carcinoma: 1.

Resección parcial: 1 .

Biopsia por congelación: 0 .

Mastectomía simple: 1 .

CUADRO NUMERO 5

La edad de las pacientes fue de 10 y 88 años.

Los sintomas fueron: tumor duro, doloroso, uno de ellos abscesado, sin retracción de la piẹl ni del pezón.

Su presunción clínica estuvo de acuerdo en 0 casos, se pensó en carcinoma en 1, se hizo resección parcial en 1, biopsia por congelación en 0 , y mastectomía simple en 1.

\section{Mastitis con necrosis grasa de mama}

Se estudiaron un total de 12 (cuadro número 6), con un porcentaje por año de 0,9 y un porcentaje de $1.0 \%$. La edad osciló $\in$ ntre $\operatorname{los} 24$ y 60 años. Su evolución fue de 1 mes a 2 años, sienco en casi todos los casos menor de 3 meses.

\section{TRAUMA CON NECROSIS GRASA DE MAMA}

Total: 12. Promedio por año: 0.9 .

Porcentaje de las 1.181 mamas estudiadas: $1.0 \%$.

.. Presunción clínica de acuerdo: 0 .

Se pensó en carcinoma: 2.

Biopsia o resección parcial: 11.

Biopsia por congelación: 1 .

Mastectomía simple: 0 .

Mastectomía radical: 1.

CUADRO NUMERO 6

Sus sintomas en orden de frecuencia fueron: tumor adhericio a la piel o planos profundos, dolor punzante, piel de naranja, adenopatía axilar y supuración por el pezón. 
La presunción clínica fue acertada en 0 casos. Se pensó en carcinoma en 2, uno de ellos con biopsia por congelación previa, positiva, para lesión maligna; que posteriormente no se encontró al hacer el estudio de la mama y los ganglios axilares. Se hizo biopsia o resección parcial en los otros 11 casos.

\section{Dilataciones de los conductos mamarios}

En los 13 años se estudiaron 15 dilataciones de los conductos mamarios (cuadro número 7 ), con un promedio por año de 1.1 y un porcentaje de $1.2 \%$.

\section{DILATACIONES DE LOS CONDUCTOS MAMARIOS}

Total: 15: Promedio por año: 1.1.

Porcentaje de las 1.181 mamas estudiadas: $1.2 \%$.

Presunción clínica de acuerdo: 0.

Se pensó en carcinoma: 2.

Biopsia o resección parcial: 12.

Biopsia por congelación: 0 .

Mastectomía simple: 2.

Mastectomía radical: 1 .

\section{CUADRO NUMERO 7}

La edad osciló entre los veintitrés y sesenta años y su evolución entre 15 dias y 5 años, siendo más frecuente en los primeros 3 meses.

Sus sintomas, en orden de frecuencia, fueron: uno o varios nódulos con diámetro que oscila entre 1 y 7 centímetros, secreción sanguinolenta por el pezón, dolor, fijación a los planos vecinos, secreción purulenta por el pezón y ulceración.

Se pensó en carcinoma en 2 , en uno de ellos por ulceración que compromete el mamelón, adherido a los planos profundos y superficiales y que deja salir pus por el pezón, en el otro por nodulación en mama izquierda a los ocho meses de mastectomía radical derecha, por adenocarcinoma.

Se hizo resección parcial en 12, biopsia por congelación. en 0 , mastectomía simple en 2 , y radical en 1 .

\section{Mastopatía quística}

En el grupo de la mastopatía quistica comprendimos los especimenes denominados "mastitis quística crónica", "enfermedad 
fibroquistica", "mastopatía o displasia mamaria", "mastodinia", "adenosis", "mazoplasia", "enfermedad de Schimmelbusch", "enfermedad de Reclus", "enfermedad quística" "hiperplasia virgiral juvenil", "hiperplasia de la lactancia", y "hiperplasia simple". In resumen, los estados benignos de la mama que no son ni inflamatorios ni verdaderamente neoplásticos en el sentido anatomopatológico de la palabra. La razón de esta agrupación nos la ca Geschickter al comentar que sustancialmente son idénticas con aumentos del estroma y proliferación epitelial, diferenciándose solo por accidentes como ser precoces o moderadas con tejido mamario denso y doloroso (mastodinia), o con nódulos más persistentes y definidos (adenosis), o con uno o más quistes de apreciable tamaño (enfermedad quística).

Se estudiaron un total de 277 en los 13 años (cuadro número 8), con un promedio de 21.3 por año y un porcentaje de $23.4 \%$.

\section{MASTOPATIA QUISTICA}

Total: 277. Promedio por año: 21.3.

Porcentaje de las 1.181 mamas estudiadas: $23.4 \%$.

Presunción clínica de acuerdo: 63 .

Se pensó en carcinoma: 30 .

Biopsia o resección parcial: 249.

Biopsia por congelación: 9 .

Mastectomia simple: 19.

Mastectomía radical: $\dot{9}$.

\section{CUADRO NUMERO 8}

La edad oscilo entre los dieciséis y setenta y ocho años, aumentando de $\operatorname{los} 20$ a los 35 y disminuyendo de los 35 a los 60 , después de los 60 solo casos aislados.

La evolución es marcadamente precoz, siendo más frecuente $\epsilon n$ el primer mes $\mathrm{y}$ disminuyendo en forma gradual hasta los 5 años, de alli. en adelante solo casos esporádicos.

Los síntomas clínicos en orden de frecuencia en nuestras historias fueron: tumor de 1 a 10 centímetros de diámetro siendo más frecuente de 2 a 7, dureza del tumor, dolor (70\%), adherencias $(50 \%)$, secreción serosanguinolenta por el pezón, quiste, tumefacción, piel de naranja, supuración y adenopatía axilar.

El cuadro anatomopatológico macroscópico puede presentarse como una tumefacción no encapsulada con un aspecto más 


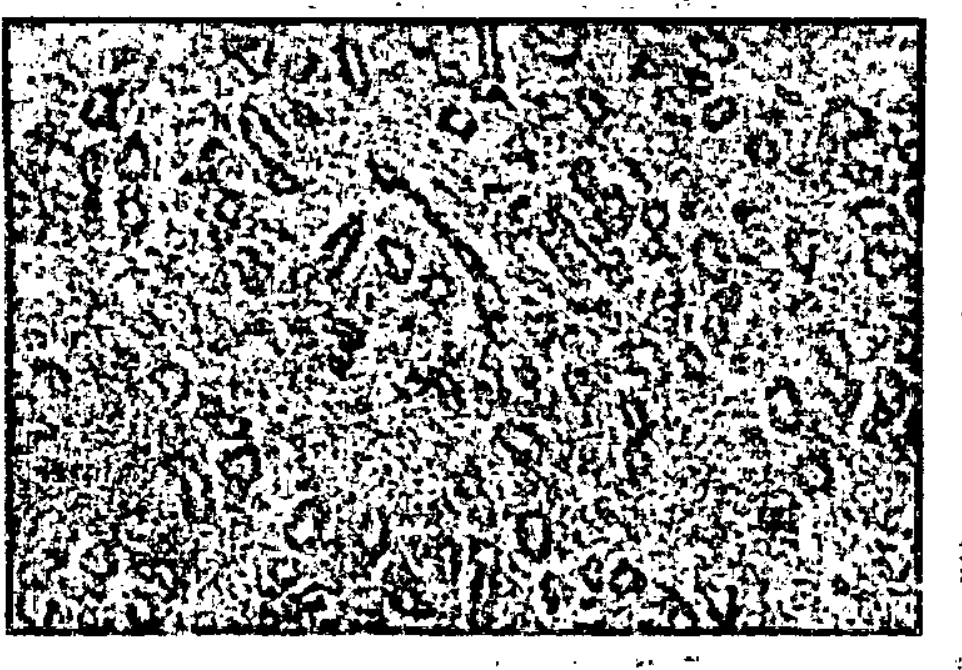

FIGURA NUMERO 9.-Mastopatía quística.

fibroso que el resto de la glándula, o como tejido.acribillado de pequeños quistes y con franca consistencia fibrosa, o como quistes de tinte aźulado en donde la parte superficial está incluida en la grasa y la profunda en tejido fibroso tenso.

Microscópicamente puede presentarse (figuras números 9.10 , 11) aumento del estroma peri e intra-canalicular, con las células de revestimiento de los canalículos reduplicadas y con secreción en los canalículos pequeños dilatados. O apreciarse una prolifeyación epitelial en los canaliculos con formación de adenomas y proliferación diseminada de los elementos ascinosos que invaden el estroma de alrededor, y dilatación de los canales terminales - acini con formación de pequeños quistes. también con aumento del estroma pericanalicular y perilobular. O presentarse dilatación o regresión de los lóbulos y dilatación de los canaliculos con secreción al lado de pequeños focos de proliferación del.epitelio; en los quistes es frecuente que el epitelio de revestimiento ciel' quiste esté reemplazado por tejido fibroso (Geschickter).

\section{Ginecomastía}

Es la hipertrofia de la glándula mamaria en el sexo masculino, histologicamente (figura número 12) se observa una.proliferación de los canales y del tejido periductal; el epitelio de los túbulos está formado por varias capas que hacen a veces proyecciones hacia el interior de su luz. 


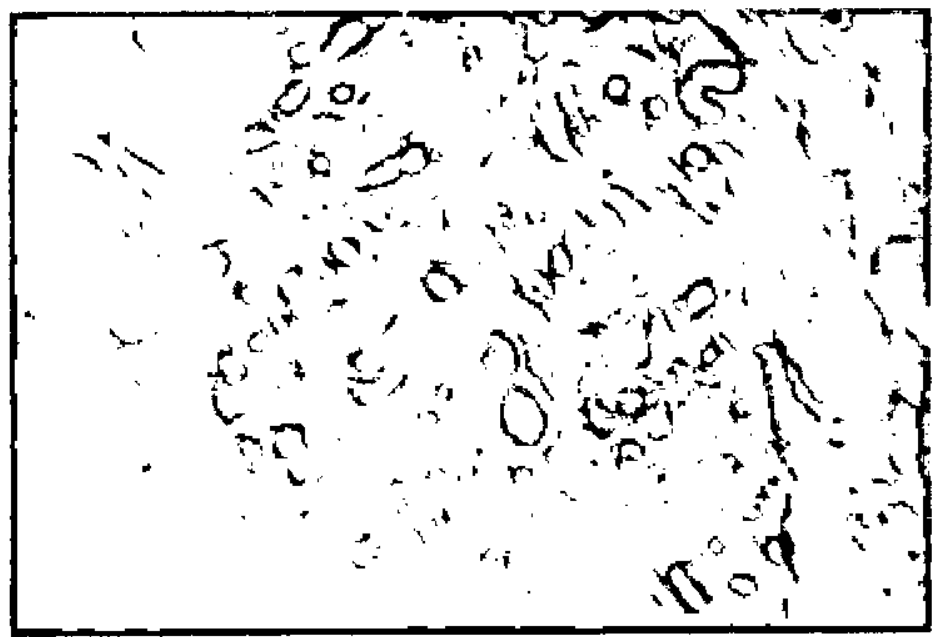

FIGURA NUMERO 10.-Mastopatía quística.

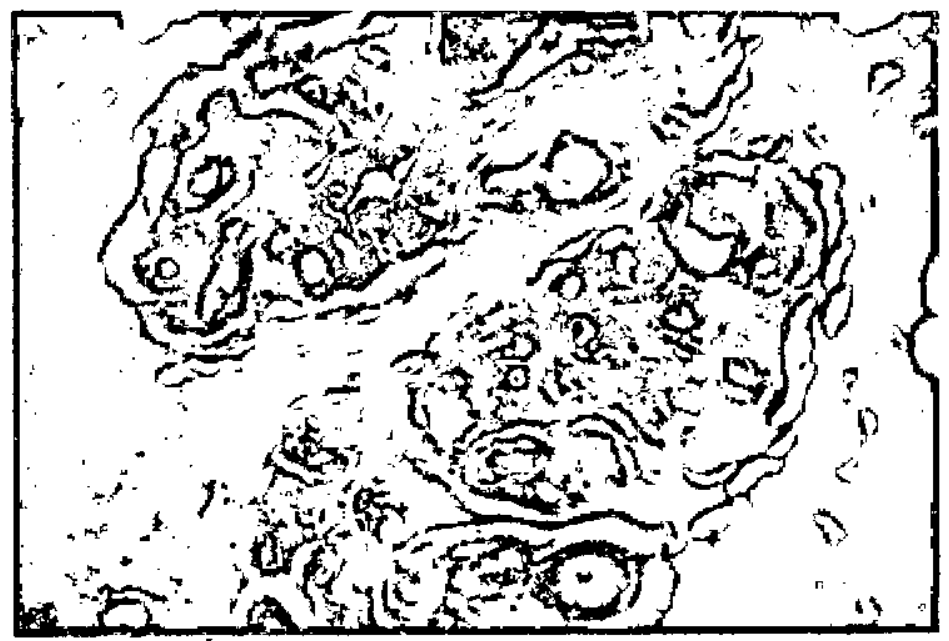

FIGURA NUMERO 11.-Mastopatia quística.

La ginecomastia se encuentra principalmente en las edades de diecisiete a veinticinco años y de 45 a 60 épocas de las modificaciones en el balance de los estrógenos y de los andrógenos; a veces se debe a la incapacidad del higado para metabolizar los estrógenos; y se acompaña con alguna frecuencia de tumores o atrofia del testículo. 


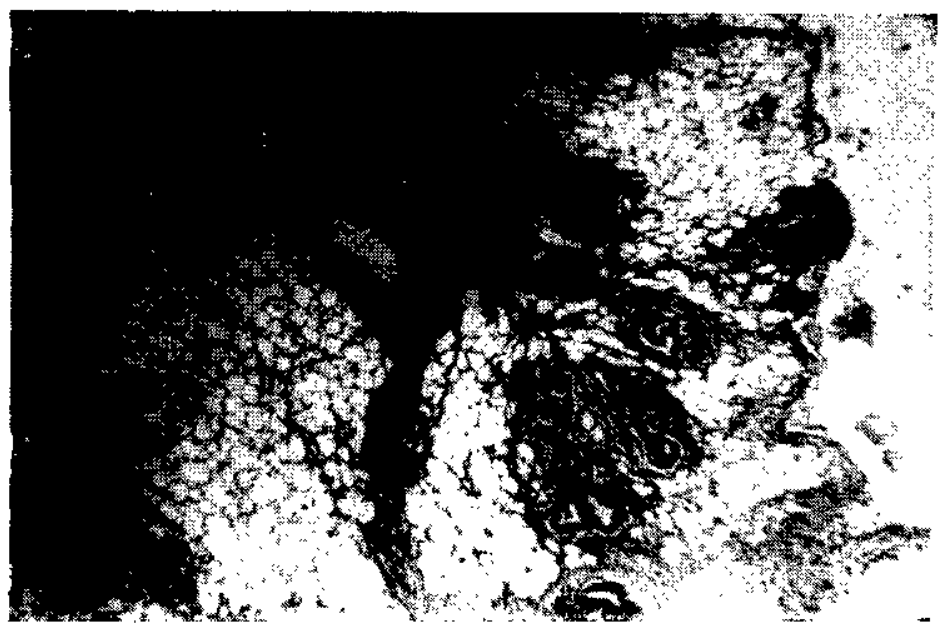

FIGURA NUMERO 12.-Ginecomastia.

De los 21 casos estudiados, encontramos 10 entre 16 y 25 años. Los signos principales que caracterizan los nuestros, son: dolor, $50 \%$; consistencia firme, $75 \%$, y todos son absolutamente benignos (cuadro número 13 ).

\section{GINECOMASTIA}

Total: 21. Promedio por año: 1.6.

Porcentaje de las 1.181 mamas estudiadas: $1.7 \%$.

Presunción clínica de acuerdo: 6 .

Se pensó en carcinoma: 0 .

Biopsia: 2.

Extirpación: 9.

Mastectomía: 6 .

\section{CUADRO NUMERO 13}

\section{Papiloma intracanalicular}

(Sinonimias, adenocistoma, cistoma papilar, papiloma intraquístico).

Se localiza frecuentemente muy cerca del pezón y se aprecia como una masa tumoral, móvil, redondeada e indolora (figura número 14).

Microscópicamente se aprecian dilataciones quísticas bordeadas por epitelio aplanado, a trechos se observan prolongaciones 


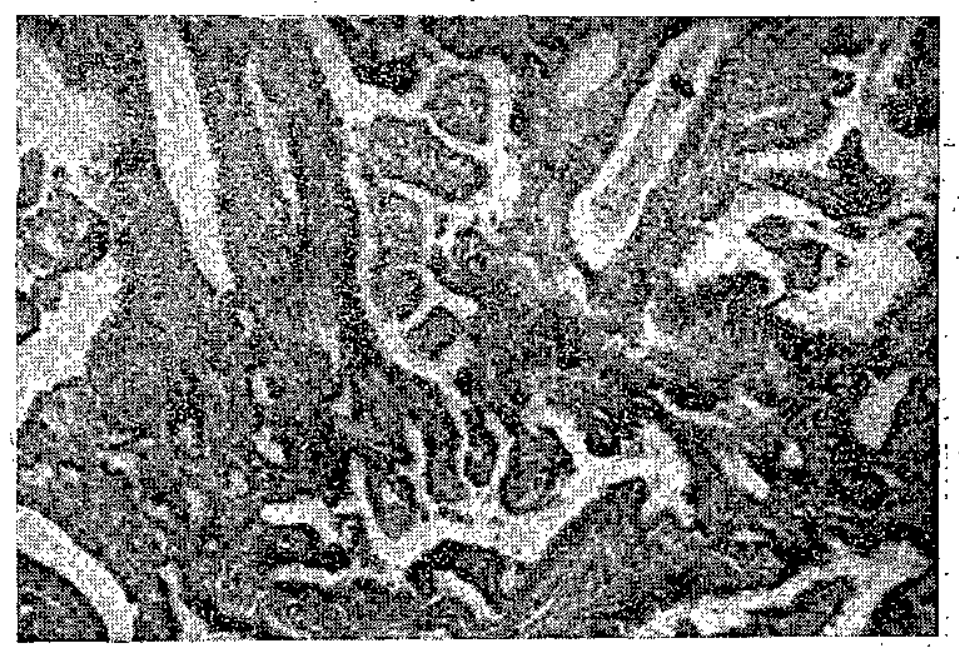

FIGURA NUMERO 14.-Papiloma intracanalicular.

pediculadas y adheridas al epitelio de la dilatación quística: Las arborizaciones papilares contienen un tallo conjuntivo, provisto ce vasos dilatados que sangran fácilmente. El epitelio de las arborizaciones es uni o pluriestratificado y el contenido quístico es frecuentemente hemorrágico, debido a la fragilidad de los vasos ce los tallos. Con gran facilidad este líquido sale al exterior en forma de descargas sanguinolentas, lo que facilita grandemente su diagnóstico por medio de la citología según Papanicolaou, y permite descartar el carcinoma.

En los 26 casos estudiados encontramos 6 . con ulceración, 5 con dolor, 8 con supuración sanguinolenta, 5 con retracción del pezón; lo cual indujo a los clínicos a diagnosticar carcinoma y así vemos que 19 fueron tratados con mastectomía (cuadro número 15).

\section{PAPILOMA INTRACANALICULAR}

Total: 26. Promedio por año: 2.0

Porcentaje de los 1.181 mamas estudiadas: $22 \%$.

Presunción clínica de acuerdo: 1 .

Se pensó en carcinoma: 7.

Biopsia: 2.

Extirpación: 5

Mastectomia: 19.

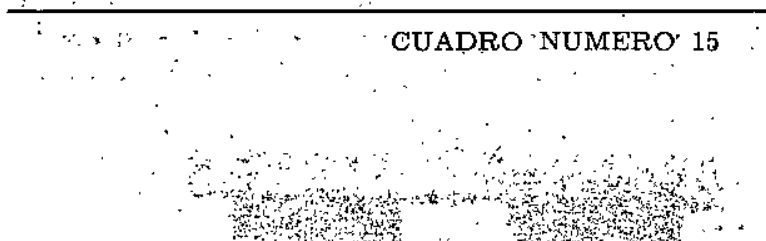




\section{Fibroadenoma}

Es un tumor duro, móvil, de superficie irregular y muy: poco doloroso, a veces completamente indoloro.

El estudio histológico revela una proliferación del epitelio de los túbulos acompañada por hiperplasia de los mismos, escasez cie la formación lobulillar y notable aumento del tejido conjuntivo periductal (figura número 16).

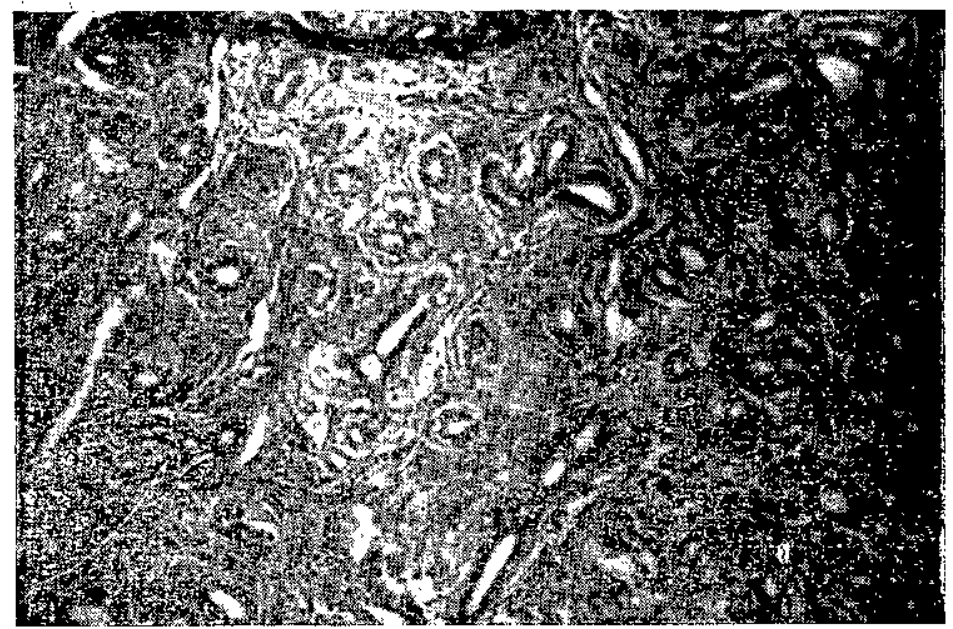

FIGURA NUMERO 16.-Fibroadenoma.

Por causa de su notable semejanza con el tejido mamario normal, ha sido llamada esta entidad por algunos "una mama clentro de otra mama".

Los fibroadenomas son más frecuentes en los periodos pre y post-adolescentes. Ocasionalmente se osifican o calcifican y rara vez se degeneran.

Durante lá gestación, los fibroadenomas sufren marcada hiperplasia que produce un notable aumento de su tamaño y regresan nuevamente después de la lactancia; parece que también hay gran relación entre estos tumores y las hormonas estrogénicas.

En nuestro material encontramos la mayor frecuencia entre los diecinueve y treinta años: 9 casos; como sintomas característicos, la movilidad en 5 casos, consistencia firme en 11, con retracción del pezón, 2, y su tamaño promedio osciló entre 3 .y 6 centí- 
metros. Fueron intervenidos con mastectomia y diagnóstico de carcinoma, 4 casos (cuadro número 17).

\section{FIBROADENOMA}

Total: 31. Promedio por año: 2.3 .

Porcentaje de las 1.181 mamas estudiadas: $2.6 \%$.

Presunción clínica de acuerdo: 10.

Se pensó en carcinoma: 2.

Biopsia: 2.

Extirpacion: 10.

Mastectomia: 4.

\section{CUADRO NUMERO 17}

\section{Fibroma intracanalicular}

Es una hiperplasia que afecta más el tejido conjuntivo que al tejido epitelial de los lóbulos. El tumor tiene más aspecto de fibroma que de adenoma. Es un tumor bien encapsulado y de consistencia blanda.

Microscópicamente, se puede apreciar una notable proliferacićn del tejido conjuntivo que trata de invaginarse en las paredes de los túbulos proyectándose dentro de su luz, formando pequeñas masas polipoides y provocando su dilatación, alargamiento y distorsión (Boyd.-Figura número 18).

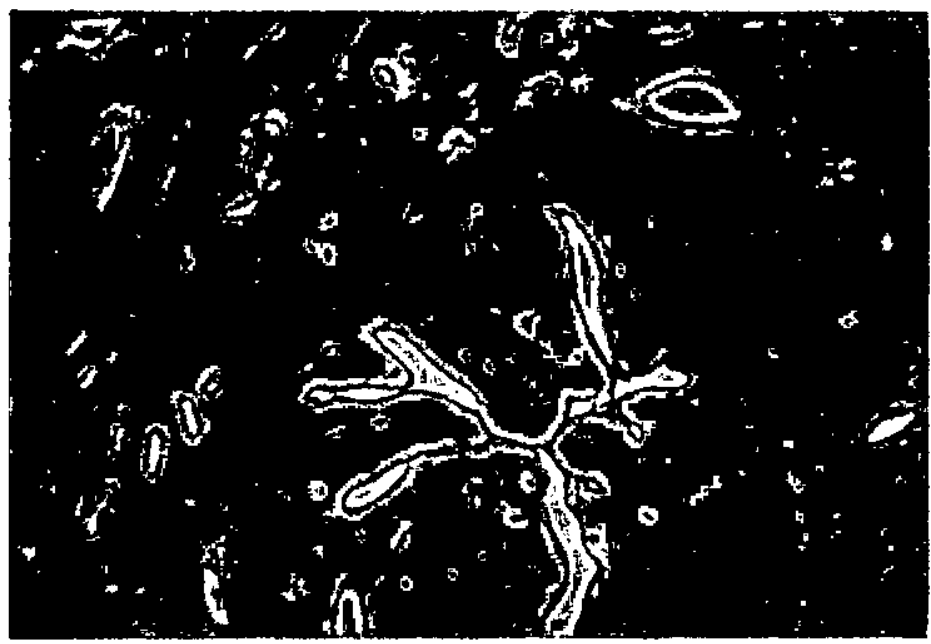

FIGURA NUMERO 18.-Fibroma intracanalicular. 
Sintomas.-En nuestro material 109 casos, encontramos el sintoma dolor en 10, movilidad en :57, consistencia firme en 58 .

A veces presentan retracción del pezón y consistencia blanda, lo que da base para confundirlas con el carcinoma. En nuestra estadística observamos este error clínico en 19 casos y como tal fueron intervenidos con mastectomía radical (cuadro número 19).

\section{FIBROADENOMA INTRACANALICUIJAR}

Total: 109. Promedio por año: 8.3 .

Porcentaje de las 1.181 mamas estudiadas: $9.2 \%$.

Presunción clínica de acuerdo: 0 .

Se pensó en carcinoma: 8.

Se pensó en fibroadenoma: 57.

Biopsia: 9.

Extirpación: 67.

Mastectomia: 8.

\section{CUADRO NUMERO 19}

\section{Fibroma pericanalicular}

Este tumor es más duro y más pequeño que el fibroadenoma intracanalicular, también como aquel, es bien encapsulado y de kuena movilidad.

Microscópicamente se aprecia la proliferación del tejido glandular y conjuntivo, éste rodea a los conductos glandulares pero sin hacer invaginación; de allí su nombre de pericanalicular (Boyd) (figura número 20).

Nuestra estadística de 73 casos revela que la mayor frecuencia de aparición se encuentra entre $\operatorname{los} 20$ y los 30 años ( 32 casos). dolor observamos en 18 casos, consistencia firme en 25 , movilidad en 26, el tamaño más frecuente oscila entre 2 y 6 centímetros. Fueron intervenidos con diagnóstico de malignidad, 7 casos; mastectomía radical (cuadro número 21 ).

\section{FIBROADENOMA PERICANALICULAR}

Total: 73. Promedio por año: 5.6 .

Porcentaje de las 1.181 mamas estudiadas: $61 \%$.

Se pensó en fibroadenoma: 31.

Se pensó en carcinoma: 5 . 


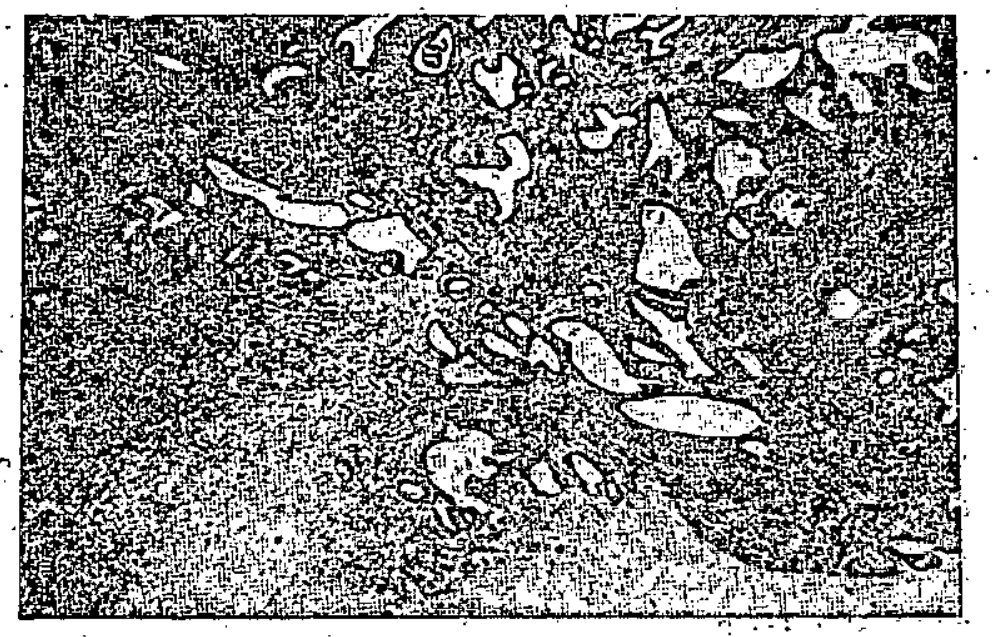

FIGURA NUMERO 20.-Fibroma pericanalicular.

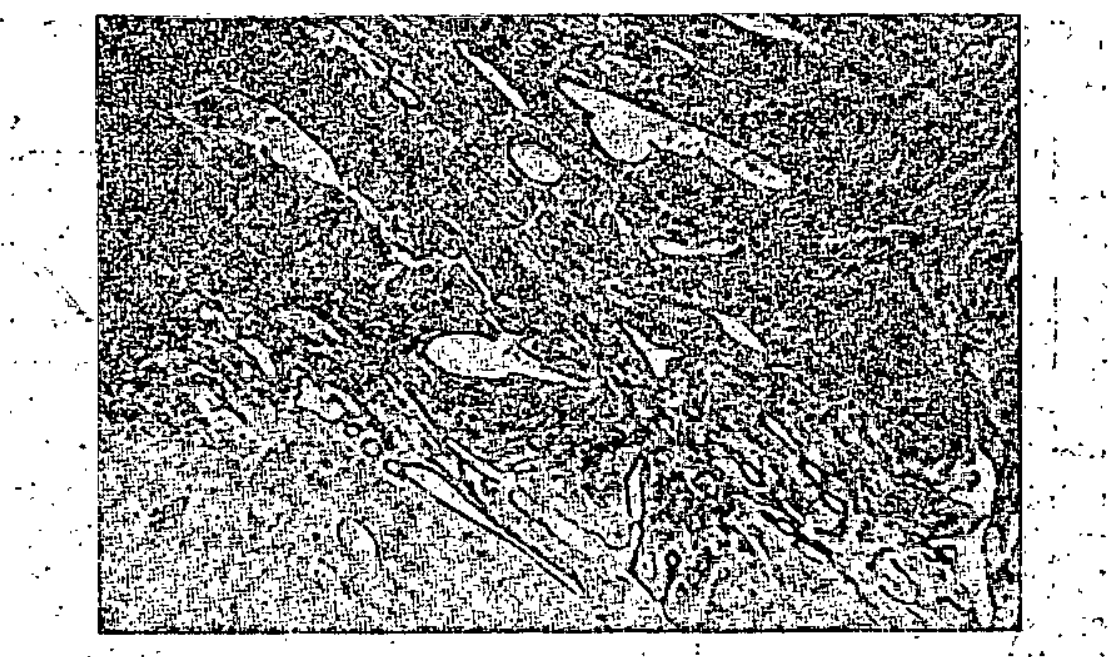

FIGURA NUMERO 22.-Fibroadenoma peri e intracañalicular.

\section{Fibroma peri e intracánaliculà}

En realidad no podemos hablar aqui de un tumor bien definido; se trata más bien de una mezcla de loș dọs anteriores: perecanalicular e intracanalicular (figura numero 22):"

- Clinicamente se aprecia una tuberosidad lobûlada: de'2a 5 centimetros de diámetro. generalmenté indolora: " 
La edad de aparición más frecuente, fue entre los 20 y los 30 años, 23 casos, y los sintomas más salientes observados lós siguientes: dolor en 15, movilidad, 21, consistencia firme, 21, retracción del pezón en ninguno (cuadro número 23 ).

FIBROADENOMA PERI E INTRACANALICULAR

Total: 34. Promedio por año: 2.6 .

Porcentaje de las 1.181 mamas estudiadas: 2.8 .

Presunción clínica de acuerdo: 0.

Se pensó en carcinoma: 1.

Se pensó en fibroadenoma: 12 .

Biopsia: 1.

Extirpación: 26.

Mastectomía: 3.

CUADRO NUMERO 23

\section{Consideraciones general,es en relación con el cáncér de máma}

\section{Frecuencia}

Desconocemos la estadistica general de la República en cuanto a mortalidad por este concepto. El diagnóstico positivo exige èl estudio histopatológico de la lesión, y el país cuenta con pocos institutos de anatomía patológica capacitados para ello. No obstante, el pormenor estadístico obtenido por nosotros, al hacer la revisión de los casos estudiados en Medellín, capital de un Departamento que cuenta con una población de un millón quiriientos mil habitantes, y que tiene un hospital dotado de medios quirúrgicos $\mathrm{y}$ de fisioterapia anticancerosa adecuada, nos puede suministrar un indice, siquiera aproximado, de la frecuencia de la enfermedad entre nosotros, toda vez que la mayoría de los casos acude a la ciudad en busca de recursos curativos. Es entendido que cosa semejante ocurre en las otras secciones del país.

El número global de nuestra serie es de 423 casos (cuadro rúmero 23), que como se refiere al lapso de 13 años (1) y 3 meses, tendríamos en promedio, por año, 32 enfermas únicamente. El número es todavia más significativo cuando lo comparamos con el de carcinomas uterinos en el mismo tiempo y en el mismo Instituto, que fue de 1.260 cervicales y. 144 corporales, por todo 1.404, con un promedio anual de 106. 
Total: 423. Promedio por año: 3.2 .

Cáncer del útero.

'Total: 1.404. Promedio por año: 106.

Instituto de Anatomía Patológica de la Universidad de Antioquia.

Cáncer de mama

Cáncer del útero

EE. UU.

Cáncer đe mama

Cáncer del útero $=0.428$.

CUADPRO NUMERO 24

Nos llama la atención que cuando en los Estados Unidos de Norteamérica la proporción entre los carcinomas de mama y útero es de 112 a 120 (1), en cambio entre nosotros es de 3 a 7.

En otros términos, por cada 120 casos de carcinomas uterinos, registran en los Estados Unidos 112 de carcinomas mamarios; proporción 0.939 , y nosotros, por 120 casos de carcinoma uterino tan solo tenemos 51 mamario, proporción 0.428 .

Estudios ulteriores se encargarán de analizar estos hechos.

Edad.-En 341 casos encontramos el dato referente a la edad $(80,6 \%)$ y en 82 no lo habia $(19,4 \%)$. El pormenor por edades es como sigue (cuadro número 25): 


\section{EDAD}

Con edad registrada: $341(80.6 \%)$.

Sin edad registrada: $82(19.4 \%)$.

\begin{tabular}{|c|c|c|c|}
\hline \multicolumn{2}{|c|}{ Edad } & Total & Porcentaje \\
\hline$-c$ & de 20 & 1 & $(0.3 \%)$ \\
\hline & a $\quad 29$ & 15 & $(4.4 \%)$ \\
\hline & a 39 & 56 & $(16.4 \%)$ \\
\hline & a 49 & 102 & $(30.0 \%)$ \\
\hline 50 & a 59 & 90 & $(26.4 \%)$ \\
\hline 60 & a 69 & 49 & $(14.3 \%)$ \\
\hline 70 & a 79 & 24 & $(7.0 \%)$ \\
\hline+ & de 80 & 4 & $(1.1 \%)$ \\
\hline
\end{tabular}

\section{CUADRO NUMERO 25}

La década fatal en nuestro estudio es la comprendida entre los 40 y los 49 años, que registran 102 casos (30\%) y la sigue con 90 casos $(26.4 \%)$ la de 50 a 59 años. Hubo 1 caso en una joven de 19 años y 15 en pacientes entre los 20 y 29 años.

Aceptado el principio que en nuestro medio la mujer entra en menopausia entre los 45 y 50 años, tenemos que $48.8 \%$ de las enfermas con edad registrada hicieron carcinoma estando en menopausia, contra $51.1 \%$ que lo presentaron durante la actividad genital o en pleno climaterio.

\section{Factor hormonal}

El papel funcional de los estrógenos en la evolución de las metástasis cancerosas será revisado más adelante cuando estudiemos el tema concretamente; no obstante, al contemplar el cuadro de las edades, observamos que el mayor porcentaje del cáncer mamario $(70.7 \%)$ corresponde a la época de la vida femenina en que hay hiperestrogenismo, entre los 40 y 65 años, debido justamente al desequilibrio hormonal resuitante de la carencia de ovulación y consiguiente déficit luteínico.

Es manifiestamente menor el porcentaje $(21,1 \%)$ en los casos de mujeres menores de 40 años, en las cuales generalmente existe un estrogenismo normal por el funcionamiento regular del ovario. El problema etiológico del cáncer aún no está resuelto, 
pero se alcanza a vislumbrar algo muy significativo cuando se estudia, la reacción de algunas localidades malignas, por ejemjio en mama y próstata, con los andrógenos y estrógenos, respectivamente.

Se argumenta con buena lógica, que durante el embarazo hay un estrogenismo muy marcado, sin que por ello aparezca el carcinoma de la mama, pero este estado hormonal está balanceado por los otros esteroides de la placenta, en tanto que en el climaterio y primeros años de la menopausia no lo está. Se adelantan estudios de investigación al respecto tendientes a controlar, con dosificaciones hormonales, la correlación del cáncer mamario y €strogenemia respectiva.

Hay un hecho significativo y es la poca frecuencia del cáncer de mama en el hombre, cuya proporción apenas alcanza al $1 \%$ del femenino, y en nuestra serie el $0.5 \%$ probablemente dekido a que los estrógenos en el varón son muy escasos.

Es conocido el cáncer experimental estrogénico en monos, conejos, y ratones, a pesar de que se complementa su acción (la estrogénica) con progesterona y andrógenos. Es fácil reproducirlo en animales envejecidos o en vía de serlo, es decir, cuando el poder regenerativo es menor. En el sér humano es frecuente encontrar tres estados patológicos, que son la hiperplasia o mastitis crónica, el fibroadenoma y el carcinoma, con patología seriada atribuible al estrogenismo.

Matrimonio y embarazo.—En el Instituto de Radium del Hospital de San Vicente de Paúl, de Medellín, especialmente destinado a la radioterapia de los tumores malignos, se han estudiado 122 pacientes, con cáncer de mama.casi todas operadas en el Servicio de Cirugia General. En las historias clínicas encontramos el siguiente pormenor (cuadro número 26):

CANCER DE MAMA - INSTITUTO DEL RADIUM III 52 A VIII 57

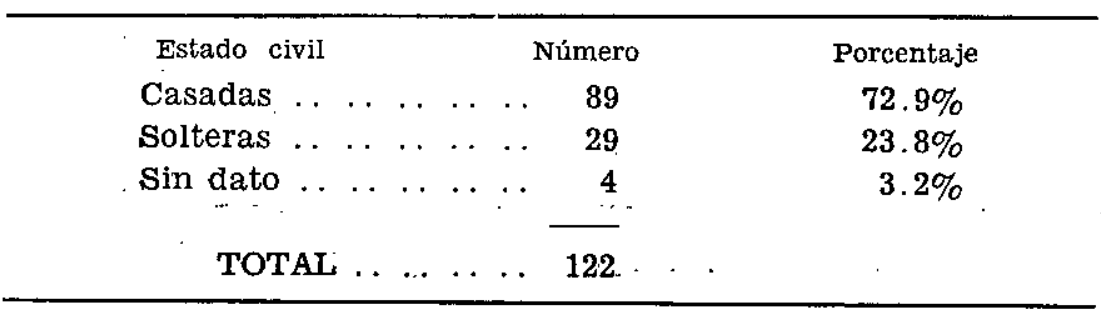




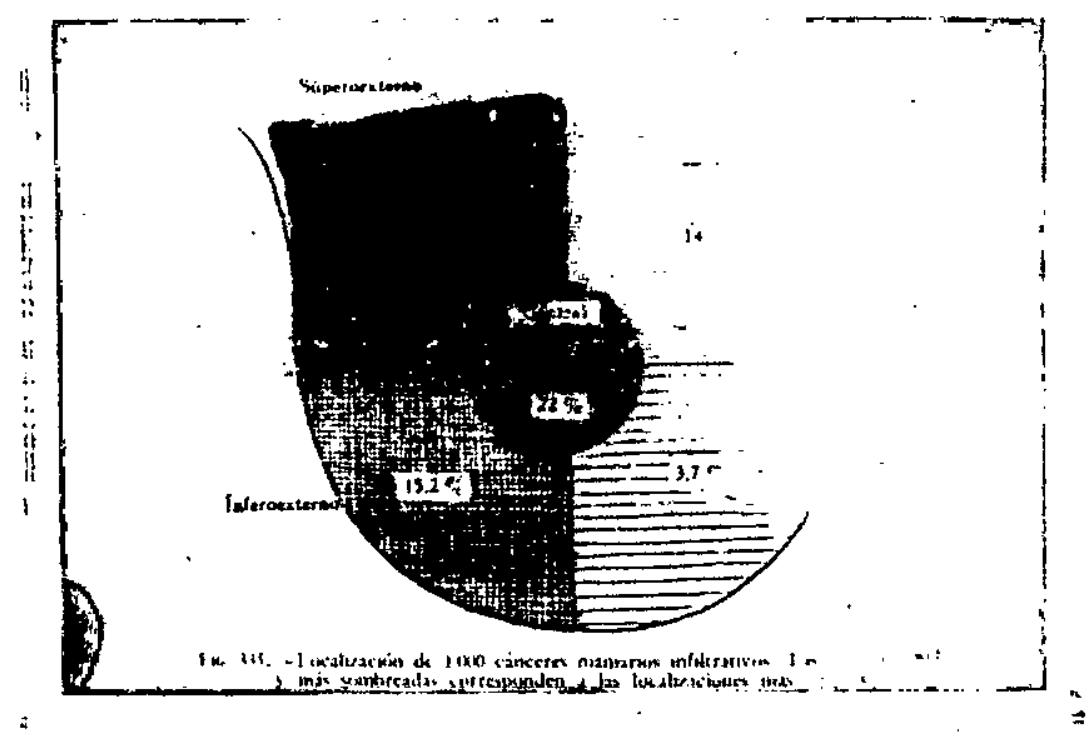

FIGURA NUMERO 27

Es mayor la frecuencia del carcinoma en las mujeres casadas, se registran 9 casos con multiparidad entre 11 y 21; 27 casos entre 6 y 10 partos; 22 pacientes entre 3 y 5 partos. y 13 que solo tuvieron de 1 a 2 partos; 8 tuvieron aborto sin parto. Las solteras atendidas no tuvieron gestaciones.

Localizacion.-Como nos fue imposible obtener el dato preciso de localización del tumor en los casos estudiados, hubimos ae acudir a otras fuentes, y al efecto encontramos (2) esta magnifica gráfica ilustrada que reproducimos en seguida (figura núinero 27).

Los porcentajes consignados se refieren a un estudio de 1.000 casos, y dan por consiguiente una idea muy clara al respecto.

El interés clínico de la localización del tumor. es especialmente en lo referente a tratamiento y pronóstico. Más o menos las $2 / 3$ están situadas en los cuadrantes externos, cuyas metástasis se hacen generalmente a la región axilar, en tanto que los de los cuadrantes internos, como veremos más adelante, se propagan al mediastino, y de hecho son de peor pronóstico.

Metástasis.-La red linfática de la glándula mamaria humana es extraordinariamente rica. Al cirujano interesa conocer la 
presencia de una red colectora sub-areolar. y del mamelón, que recibe los linfáticos de los lóbulos y alvéolos por conductos que corren paralelos a los canales galactóforos, y de alli parten vasos linfáticos en todas direcciones, siendo los principales: a) Los tributarios de la axila y región vecina sub-clavicular; b) Los que siguen la ruta de la mamaria interna en busca de los ganglios del mediastino; c) Los tributarios del hígado y zona diafragmática siguiendo los linfáticos abdominales; d) Unos pocos que siguen a la región comprendida entre el grande y pequeño pectoraI; e) Algunos que buscan la red linfática anastomótica del seno opuesto (mamaria cruzada) ; f) Los de la vía sub-esternal, igualmente tributarios del mediastino; g) Los linfáticos propios de los ganglios sub-clavios, y h) La red superficial de los 2 cuacrantes inferiores que van a la red abdominal.

Esta numerosa red linfática nos explica la variedad de sitio en que se encuentran las metástasis y su frecuencia relativamente grande en caso de carcinoma mamario (cuadro número 28).

\section{METASTASIS}

Cánceres estudiados: 423.

Con metástasis: $198(46.8 \%)$.

\begin{tabular}{lrrr}
\multicolumn{1}{c}{ Variedad } & Total & Con metástasis & Porcentaje \\
\hline Adenocarcinoma & 287 & 148 & $51.5 \%$ \\
Esquirroso & 90 & 43 & $47.7 \%$ \\
Fibrosarcoma & 5 & 2 & $40.0 \%$ \\
Paget & 4 & 1 & $25.0 \%$ \\
Comedón & 10 & 3 & $30.0 \%$ \\
Intracanalicular & 9 & 1 & $11.0 \%$ \\
\hline
\end{tabular}

CUADRO NUMERO 28

El cuadro anterior orienta al clínico en el sentido de la alta frecuencia de las metástasis halladas en el material estudiado en el Instituto de Anatomía Patológica ya mencionado, que alcanzó al $46,8 \%$, o sea prácticamente la mitad de todos los casos vistos.

En cuanto a invasión y localización orgánica de las metástasis, es conveniente recordar que después de los ganglios linfáticos se encuentran en series de varios autores como sitios preferenciales los pulmones con un promedio de $58 \%$; pleura, $45 \%$; 
hígado, $54.2 \%$; huesos, $40.2 \%$ (cuerpos vertebrales, coxales y extremidades superiores de húmero y fémur), piel, 40\%; mama cpuesta, $10.4 \%$; glándulas suprárrenales, $38 \%$, vienen luego, con números menores, las metástasis al cerebro, ovario, bazo, etc.

Es interesante el estudio de las vias linfáticas y venosas por medio de las cuales se hace la propagación de la enfermedad. Porque se entiende perfectamente el por qué los ganglios axilares, sub-clavios y mediastinales estén invadidos; y también la manera como por la vía del canal torácico superior y vena cava corresporidiente, el material celular canceroso coloniza en el pulmón. En cambio, otras localizaciones, como la de los cuerpos vertebrales, huesos craneanos, pelvis ósea o extremidades superiores de fémur y húmero, son más difíciles de explicar. Al respecto ha demostrado recientemente Batson la existencia de un plexo vertebral, avalvular, constituido por venas vertebrales que reciben sangre de las cavidades toráxica y abdominal, en el momento de algún esfuerzo de tos, por ejemplo, o cualquier otro que aumente la presión intra-abdominal. Tendriamos entonces que, siguiendo el curso de las venas intercostales y el plexo mencionato, y por el mecanismo de la vía retrógrada frecuentemente visto en cancerología, el carcinoma mamario invade el sistema óseo en cuestión. En esta forma se demuestra que es necesario revaluar el antiguo concepto de que la via linfática tenía la exclusiva para la diseminación del carcinoma epitelial, y la sanguínea para el sarcoma.

Las metástasis óseas son tardias, en un promedio de 30 meses, en tanto que las ganglionares de axila suelen aparecer entre 6 meses y un año, con un promedio de $81 / 2$ meses.

El problema máximo del cáncer mamario lo constituye las metástasiș. En una mayoria nos es imposible su localización en los primeros estadíos de la enfermedad. A medida que ella avanza la invasión se hace mayor. Para formar concepto, vamos a estudiar las localizaciones finales en caso de muerte. 
AUTOPSIAS EN CASOS DE CARCINOMA DE MAMA HECHAS DE 1944 A 1957 CON LAS LOCALIZACIONES ENCONTRADAS (Hospital de San Vicente de Paúl)

\begin{tabular}{|c|c|c|c|c|c|c|c|c|c|}
\hline $\begin{array}{l}\text { Fecha } \\
\text { Autopsia numero }\end{array}$ & & & $\begin{array}{c}\text { VIII_44 } \\
35 \\
\end{array}$ & $\begin{array}{c}\mathrm{II}-47 \\
130 \\
\end{array}$ & $\begin{array}{c}\text { III-54 } \\
693 \\
\end{array}$ & $\begin{array}{c}\text { IX-54 } \\
786 \\
\end{array}$ & $\begin{array}{l}\mathrm{I}-56 \\
1062 \\
\end{array}$ & $\begin{array}{c}\text { VII-57 } \\
1657 \\
\end{array}$ & 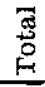 \\
\hline Hígado. . . . . . . . & & . & . & + & + & + & + & + & 5 \\
\hline Ganglios Mediastinales . & & $\cdot$ & • & + & + & $+\cdot$ & + & + & 5 \\
\hline Ganglios Aórticos . . . & & ${ }^{\circ}$ & & & & & + & + & 2 \\
\hline Ganglios Axilares . . . & & 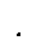 & + & + & & + & & & 3 \\
\hline Pulmón . . . . . . . . . & & . & 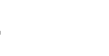 & & + & + & & + & 3 \\
\hline Páncreas . . . . . . . & & . & & + & & & + & & 2 \\
\hline Músculos Pectorales . . & & . & + & & & + & & & 2 \\
\hline Pleura. . . . . . . . . & - & . & & & & & & + & 1 \\
\hline Estómago . : . . . . . . & . & . & & & & + & & & 1 \\
\hline $\begin{array}{l}\text { Ganglios Mesentéricos } \\
\text { Ganglio }\end{array}$ & 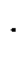 & . & & & & & + & & 1 \\
\hline Supraclavicular . . . . & & • & & & & + & + & & 2 \\
\hline Riñón Médula Osea. . . & & • & & & & + & & & 1 \\
\hline Cuerpos Vertebrales . & & & & & 1- & & & & 1 \\
\hline Costilla . . . . . . . . . & & . & & & & + & & & 1 \\
\hline Tráquea . . . . . . . & & . & & & . & + & & & 1 \\
\hline Suprarrenal . . . . . . & & $\cdot \cdot$ & & & & + & & & 1 \\
\hline Piel . . . . . . . . . . . & & . . & & ' & & + & & + & 1 \\
\hline Vesicular Biliar . . . . & & . & & & & + & & & 1 \\
\hline Cerebelo . . . . . . . & & . & & & & + & & & 1 \\
\hline Cerebro . . . . . . . . . & & . & & + & & & & & 1 \\
\hline Utero . . . . . . . . . & & . & & + & & & & & 1 \\
\hline
\end{tabular}

CUADRO NUMERO 29

Es notorio el alto porcentaje de metástasis a nivel del hígado en esta pequeña serie (83.3\%), e igual guarismo encontramos en la invasión a los gánglios del mediastino; en pulmón y gánglios axilares se hallaron 3 casos $(50 \%)$ : en uno de ellos, las dos localizaciones a la vez, y en los restantes, independientemente, dos $y$ dos.

Vienen luego, en orden decreciente, el páncreas, los múscuIos pectorales, los gánglios supraclaviculares y aórticos con dos $(33 ; 3 \%)$; y por último con solo una, las demás especificaciones anotadas :en el cuadro (16.6\%).

Es prudente anotar que no hubo un solo caso sin metástasts ganglionares, en una y otra región, en tal forma, que si se hu- 
biesen reunido todas bajo el nombre de metástasis ganglionares, se habría registrado el $100 \%$.

En estudios de autores extranjeros (4), y en series numerosas, encontramos por ejemplo, en hígado, índices menores $48.6 \%$. Gross; 59\% Warren y. Witham; 55\% Saphir y Parker. Lo mismo en algunas de las otras localizaciones, todo lo cual es prudente tener en cuenta para estudios ulteriores.

\section{ANATOMIA PATOLOGICA \\ Variedades histológicas}

La clasificación de los tumores malignós de la glándula mamaria ha sido motivo de estudio muy variado, sin que hasta el presente se haya llegado a un acuerdo definitivo. Algo semejante ocurre con los carcinomas del ovario, y eso nos ha permitido el siguiente cuadro que incluye las 423 pacientes motivo de la presente comunicación (cuadro número 30 ).

\section{VARIEDADES HISTOLOGICAS}

\begin{tabular}{lrc}
\hline variedad & Total & Porcentaje \\
Adenocarcinoma & 267 & $67.8 \%$ \\
Infiitrativo & & \\
Esquirroso & 90 & $21.3 \%$ \\
Comedón & 10 & $2.4 \%$ \\
Intracanalicular & 9 & $2.1 \%$ \\
Gelatinoso & 7 & $1: 6 \%$ \\
Metástasis & & \\
Carcinomatosa & 6 & $1.4 \%$ \\
Sarcomas & 5 & $1.1 \%$ \\
Paget . & 4 & $0.9 \%$ \\
Quiste canceroso & 4 & $0.9 \%$ \\
Papilar & 1 & $0.2 \%$ \\
Inflamatorio & 0 & $0.0 \%$ \\
\multicolumn{1}{c}{ Totales } & 423 & \\
\hline
\end{tabular}

CUADRO NUMERO 30

Hemos denominado adenocarcinomas infiltrativos o difusos a) grupo más numeroso de la serie $(67,8 \%)$, o sea, dentro del concepto de adenomas malignos, a todas aquelias neoformaciones lobulares difusas, irregulares, sin reacción especial del estroma en ningún caso, ni circunscrita ni quística. Es entendido que re- 


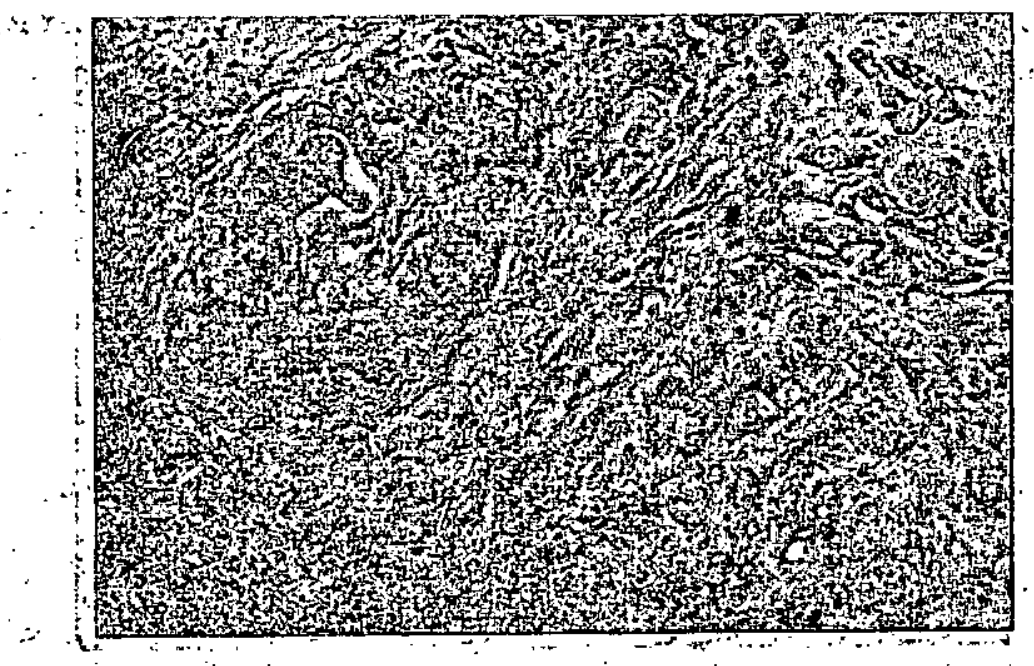

FIGURA - NUMERO- 31:-Adeno-carçinoma.

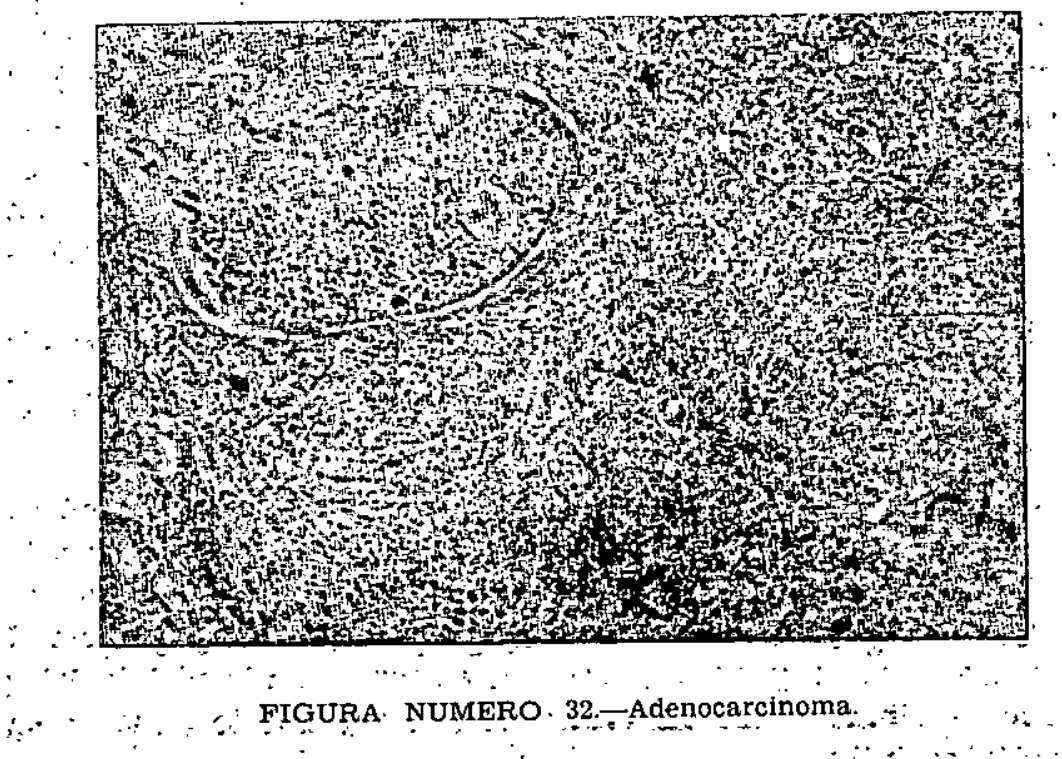

presenta solo. un grupo de los adenocarcinomas de células gländularès, pues éstọs, en realidad, constituyen el 90\% de todos los carcinomas del seno (figuras numeros 31 y 32 ). $\ldots \ldots, \ldots, \ldots$ - Aunque - el esquirro es el mismo adenocarcinoma infiltrativo que acabamos de mencionar, lo hemos clasificado aparte. por sus caracteristicas macro y microscópicas especiales que lo caracte- 


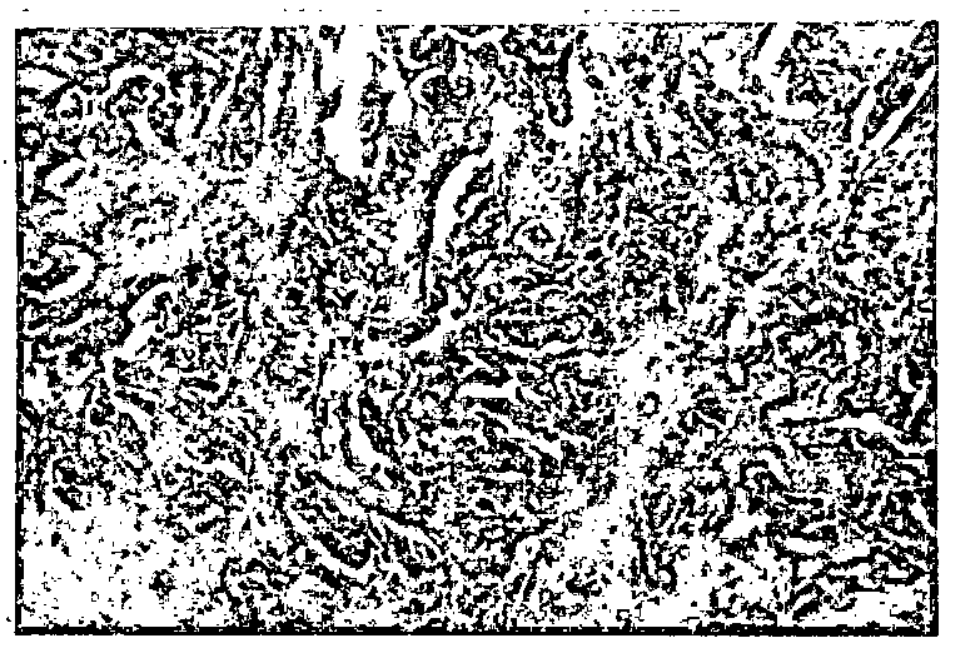

FIGURA NUMERO 33.-Esquirroso.

rizan: a) Su forma de crecimiento en cordones o digitaciones alargadas. en lugar de invadir en masa irregular como lo hace el difuso; b) La reacción del tejido conjuntivo perilobulillar que trata de oponer una barrera esclerosa, densa, indurada, a la invasión celular maligna, y que termina por darle a la mama una consistencia leñosa muy especial. En los casos estudiados encontramos el $21.3 \%$ de la serie (figura. número 33 ).

En seguida encontramos, los cánceres circunscritos, correspondientes al carcinoma tipo comedón, al adenocarcinoma papilar y al gelatinoso. Registramos 10 casos del tipol comedón (2.4\%), 9 del canalicular $(2.1 \%)$ y 7 del gelatinoso (1.6\%).

El tipo comedón fue descrito primeramente por Bloodgood en 1893. al estudiar el carcinoma de los canalículos terminales y le cio justamente el nombre de "comedo cáncer". La palabra comedón es de poco uso en nuestro lenguaje corriente y designa el grano sebaceo con puntico negro que se forma en la piel facial y salẹ al exprimirlo entre los dedos; más comúnmente se le llama también espinilla.

Efectivamente, cuando se hace un corte del tumor, se observa la salida de comedones por los canalículos que corresponden a agrupaciones celulares cancerosas aprisionadas dentro de los pequeño: tubos canaliculares. En la gran mayoría de las veces el tumor existe tal cual se ha descrito, pero con el andar del tiempo, algunas veces en el curso de muchos años, la masa neo- 


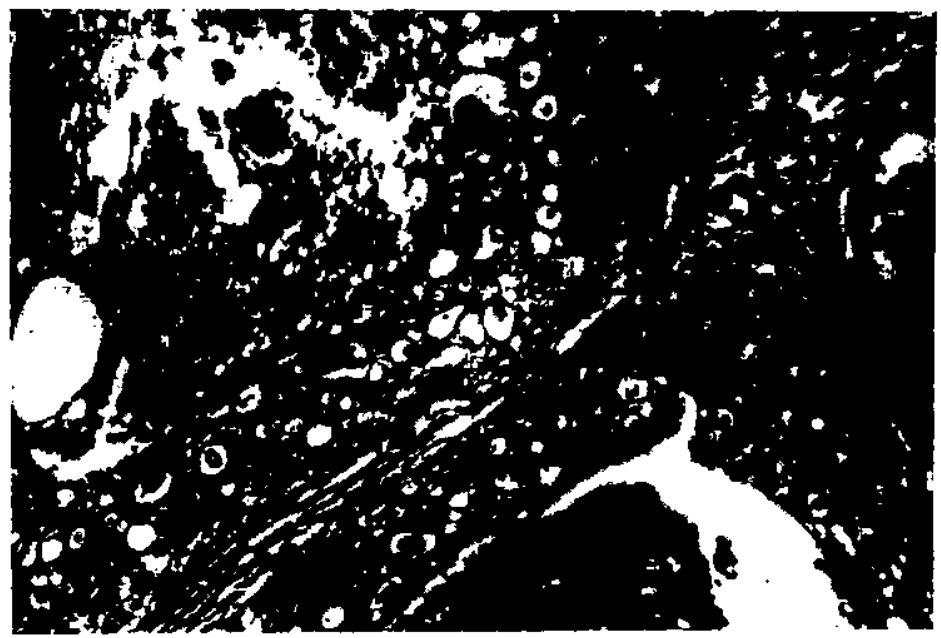

FIGURA NUMERO 34.-Comedón.

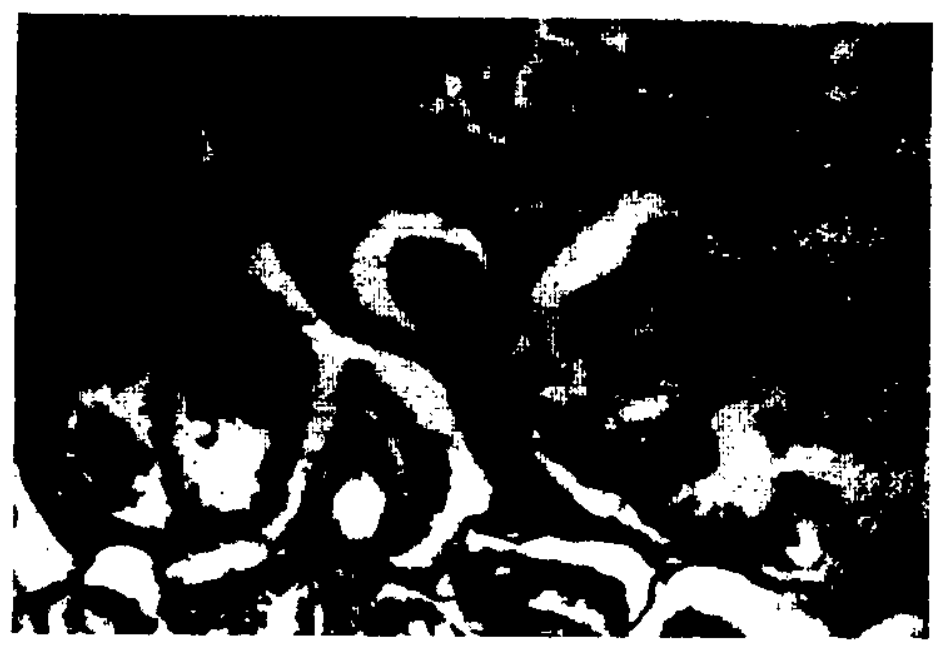

FIGURA NUMERO 35.-Intracanalícular.

plásica no sale del cauce y se hace infiltrativa dando lugar a un tipo comedón especial con caracteres anatómicos y clínicos de mayor gravedad (figura número 34 ).

El segundo sub-grupo de circunscritos lo forma el carcinoma papilar intracanalicular: Se inicia generalmente en los canales mayores inmediatamente por debajo del pezón (figuras números 35 y 36 ). 


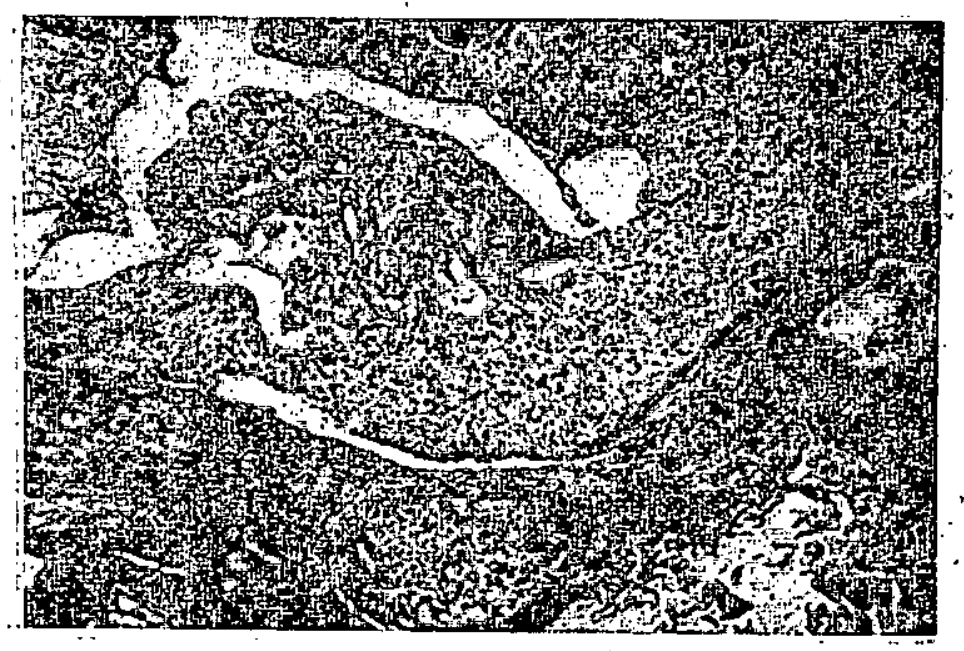

PIGURA NUMERO 36.-Intracanalicular.

: Alcanzan gran tamaño aunque sur. evolución es lenta: Están constituídos por yemas cancerosas con bastante tendencia a sangrar;: permanecen encapsulados. por algún tiempo, para iluego romperla en un tramo pequeño y dar asi comienzo a la forma mixta caracterizada por tumor intracanalicular encapsulado y al mismo tiempo difusa e infiltrante.

'Por último nos encontramos con el carcinoma gelatinoso qué solo representa el $1.6 \%$ de la serie; más o menos, el mismó por- centaje hallado en estudios más numerosos como el de Lee, Hauser y Pack. Después'en varias épocas se han hecho publicaciones aisladas hasta el año de 1934, cuando se hizo la recopilación de todos los casos publicados por los autores antes mencionados que preciso su frecuencia entre 1 y $2 \%$ de los carcinomas de mama (figura número 37.).

El tumor tiene como característica macroscopica una estruciura siropọsa que le ha valido el nombre de carcinoma gelatinoso de la glándula mamaria:

\section{Cáncer, de Paget}

\section{$\therefore$ : Unicamente 4 casos se encuentran en la serie, que equivalen} prácticamente al 1\%: Es uno de los "pocos ejemplares tumorales malignos de la mama, que no tiene relación histológica con. la glándula misma: : $:$

$\therefore$ El tumor está formado por células derivadas de epitelio estratificado, que se inicia a semejanza del carcinoma cervical ute- 


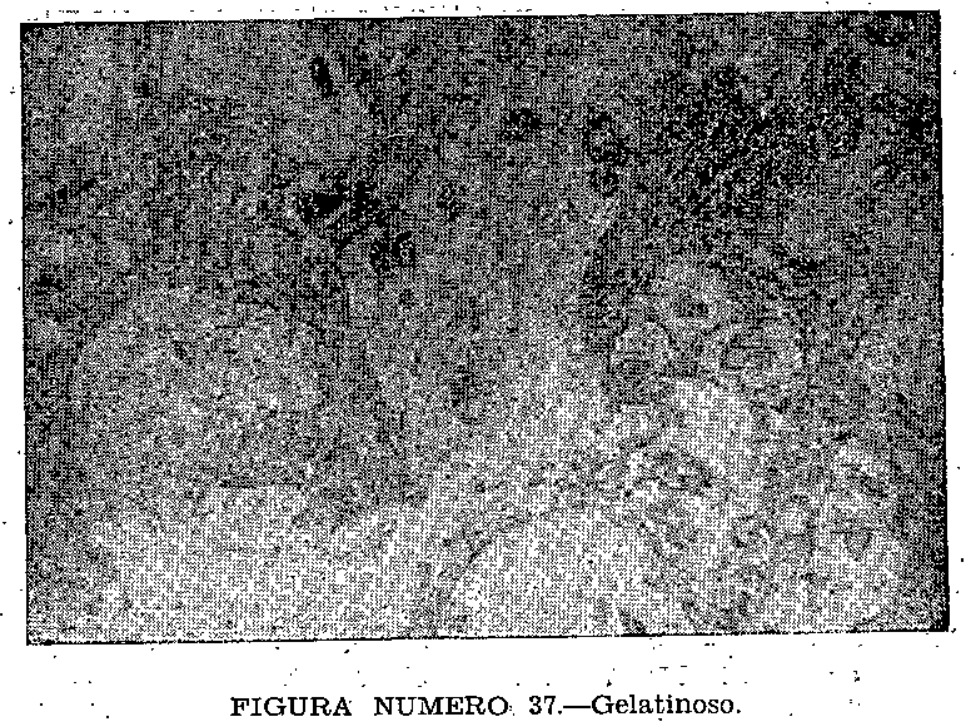

rino en"el"sitio de transición“ de "los epitelios, es decir, en el punto donde el epitelio malpighiniano se continúa con el que tapiza los canales galactóforos. En un principio la lesión : suele ser tan discreta que solo abarca el pezón o pezón areola, y ni siquiera se palpa tumor subyacente. Más tarde, cuando los canales están fran camente comprometidos, se aprecia ya el tumor. Se han descrio unas, células especiales que llevan el nombre de Paget, y que no son específicas por cuanto que también se los han encontrado en tumores vulvares y otras localizaciones similares. La enfermedad de Paget; del pezón, como también se la llama, es de marcha lenta y de malignidad un tanto atenuada, sin desconocer que es un carcinoma mál implantado y susceptible de generalizarse como - los démás (figuras números 38 y 39).

El quiste canceroso con solo 4. casos en nuestro medio $(0,95 \%)$, no es propiamente una varieda d histológica diferente cie las descritas: en ocasiones es un canalicular que se ha hecho quístico, o más extraño aún un carcinoma infiltrativo con infección y necrosis central. Ultimamente se ha dado el nombre a la entidad conocida como cáncer neomamario quístico: "

El hecho apreciable de una maśa quística que se puede puncionar para definir situaciones de diagnóstico y tratámiento, : ha hecho explicable su colocación en renglón aparte. Estos quistes son siempre de paredes engrosadas y tapizadas por células cancerosas, que dan metástasis como los demás carcinomas (figura número -40). 
440. REVISTA COLOMBIANA DE OBSTETRICIA YY GINECOLOGIA
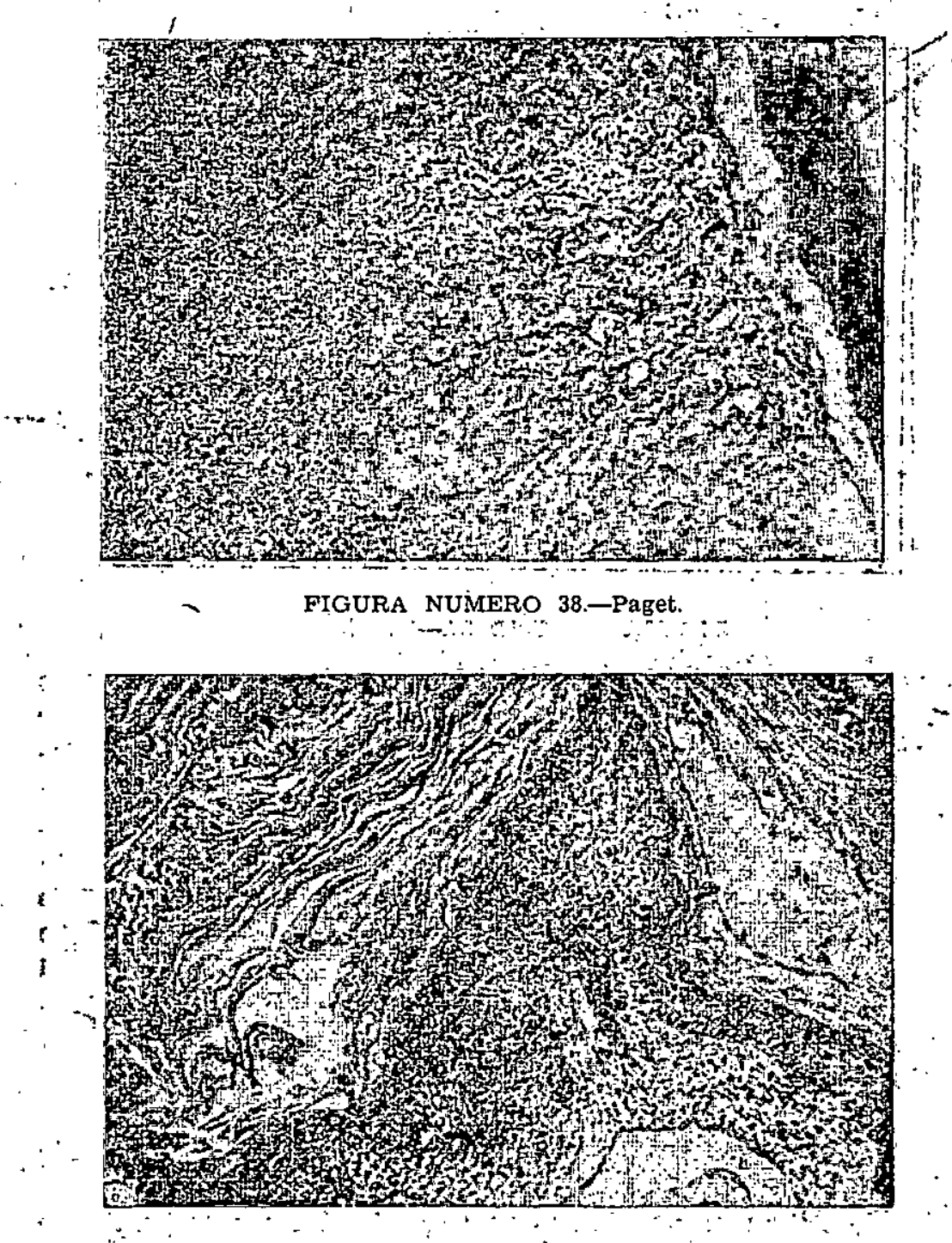

FIGURA NUMERO 39

El quiste canceroso no es propiamente igual al adenocarcinoma papilar típico, del cual solo registramos un caso $(0.2 \%)$, aunqu'e"su frecuencia es' muchísimo mayor en' las estadisticas : mundiales: El adenocarcinoma papilar puede en muchas ocasio-? nes ser quístico y: dar. lugar a confusiones; : pero lạ verdad es que siempre está encapsulado, excepto en algún pequeño 'punto, $y$ ' que al abrir el tumor se observa su morfologia papilar, que 'al 'la-": 


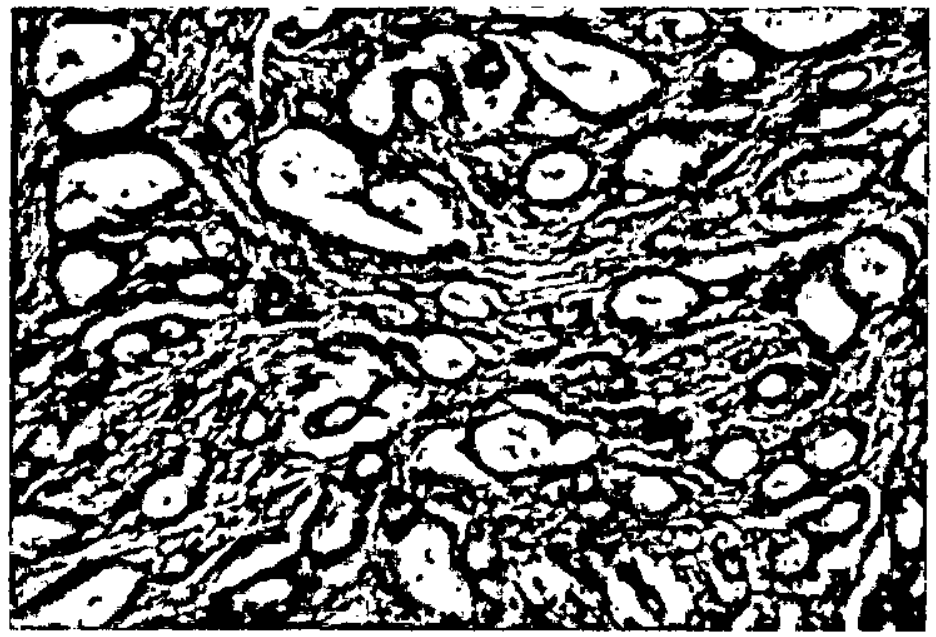

FIGURA NUMERO 40.-Quiste canceroso.

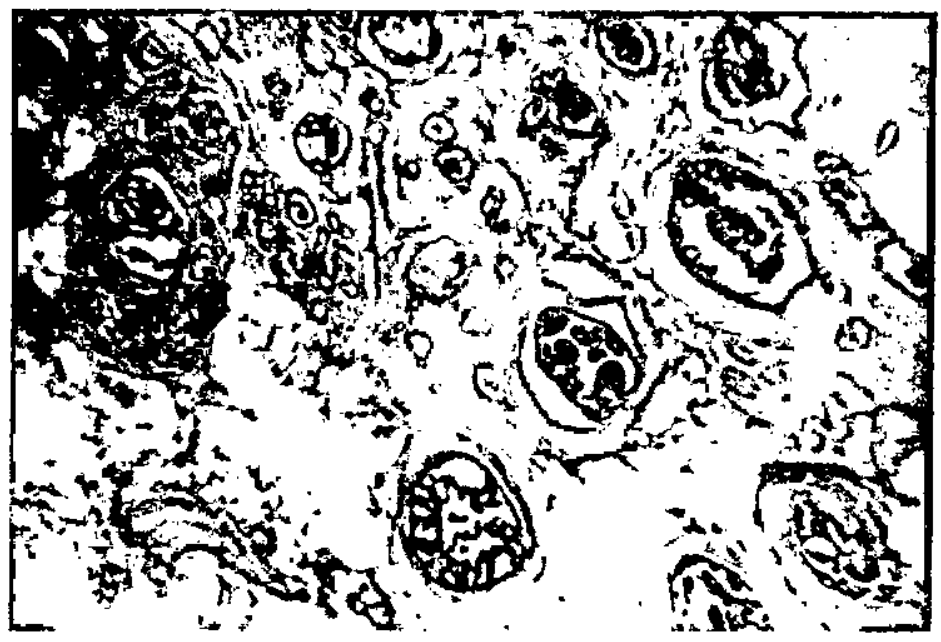

FIGURA NUMERO 41.-Papilar.

var con agua o suero se hace más aparente. Las vellosidades pudieran confundirse a simple vista con la neoformación papilar henigna, con tallos tapizados por.células bien ordenadas, en tanto que en el adenocarcinoma papilar se observan anomalías altamente celulares. mitosis, etc. (figuras números 41 y 42). 


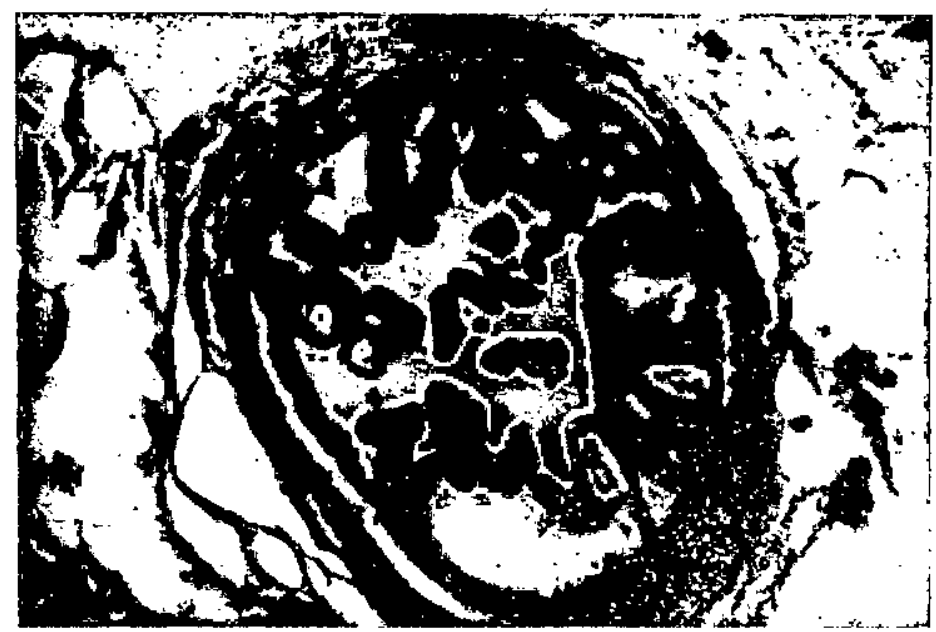

FIGURA NUMERO 42.-Papilar.

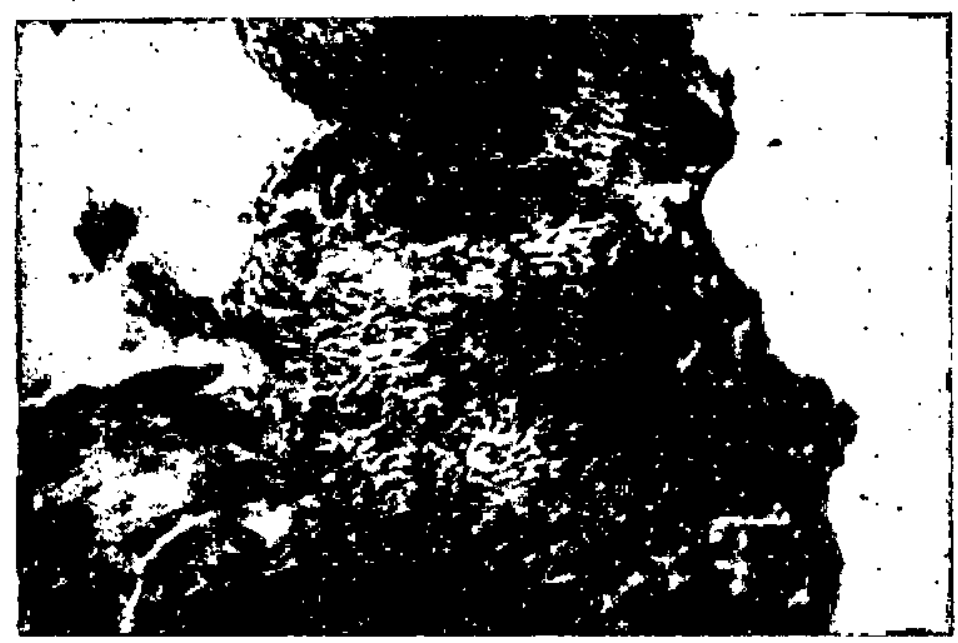

FIGURA NUMERO 43.-Sarcoma.

Encontramos. por último, en la serie estudiada 5 sarcomas (1.1\%), numero que guarda armonia con el similar de estudios comparativos en Estados Unicios. En efecto, Sailer (7), anota la proporción del sarcoma por cada 100 carcinomas de la glándula mamaria.

- Es sabido cue el tejido mesenquimatoso es muchísimo más abundante en la mama que el epitelial, excepto naturalmente 


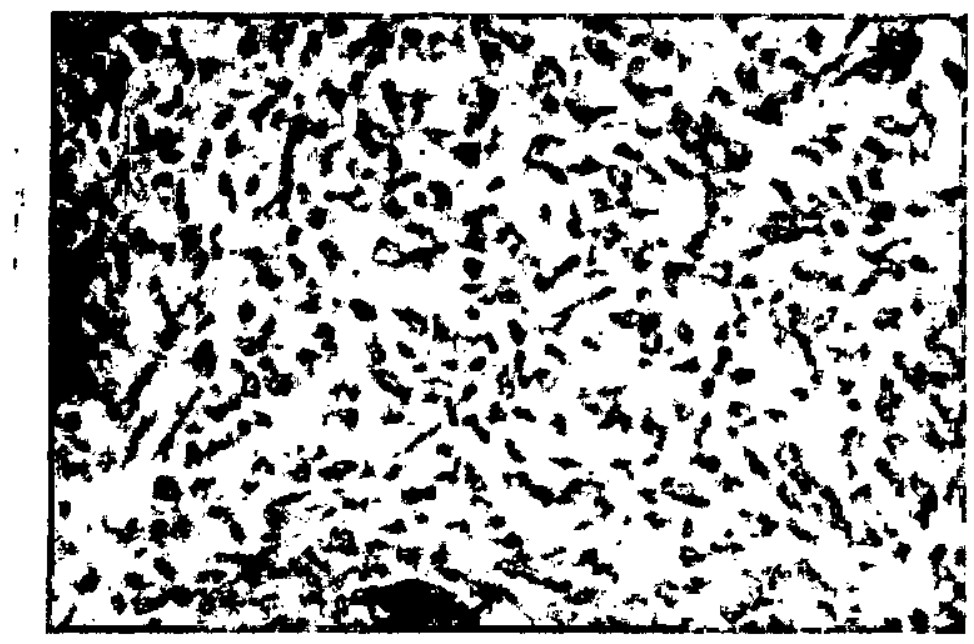

FIGURA NUMERO 44.-Sarcoma.

durante la lactancia. y sin embargo, vemos que la proporción es inversa.

Los dos grupos principales lo forman los fibrosarcomas y los adencsarcomas. Los primeros son tumores exclusivamente conjuntivos. en tanto que en los adenosarcomas derivados naturalmente de los fibroadenomas, encontramos agrupaciones celulares. de origen epitelial (figuras números 43 y 44 ).

En la imposibilidad de dar descripciones completas de los cuadros clinicos correspondientes a tan variada patologia, nos vamos a limitar a un comentario ligero de algunos síntomas en telación con nuestros casos.

Retraccion del pezón.--Solamente el 13\% (55 casos) presentaron la clásica retracción del pezón. En los estadios finales de la enfermedad el sintoma puede presentarse hasta en el $90 \%$. pero no es lo mismo cuando el tumor tiene menos de 5 centímeiros de diámetro. La retracción del pezón no es patognomónica de carcinoma. De hecho se encuentra en algunos casos de fibroadenoma o de mastitis crónica de la lactancia, también en casos de mastitis crónica supurada, adenosis, mastitis de células plasmáticas, papiloma y dilatación de los conductos. Existe también la retracción congénita del pezón casi siempre consecuencial a la mastitis neonatorum.

La retracción del pezón acompañada de tumor mamario. sin metástasis axilares, no basta para formular diagnóstico, ni menos aun para tomar una determinación radical. 
Se encuentra además la protusión del pezón que, sin ser patognomónica, es distintiva del adenocarcinoma gelatinoso.

La retracción de la piél tan solo se presentó en 6 casos $(1.4 \%)$.

Piel de naranja.-La piel de naranja es un síntoma más frecuente, como puede verse en el cuadro siguiente (cuadró número 45):

PIEL DE NARANJA

\begin{tabular}{lcrl}
\hline Variedad & Total & Porcentaje : \\
\hline Adenocarcinoma & 12 & $4 \%$ & $\vdots$ \\
Esquirro & 10 & $11.1 \%$ & \\
Comedón & 1 & $10.0 \%$ & \\
\hline
\end{tabular}

CUAADRO NUMERO 45

Estos fueron los datos relatados en los protocolos de anatomía patológica.

No obstante, creemos que pueda haber una apreciación confusa al respecto, tal vez equivocada, por el hecho de que no es lo mismo el análisis del síntoma en el paciente mismo, es decir, en el terreno clínico, que cuando se le estudia en la pieza anatómica en el laboratorio.

Hacemos esta afirmación porque al conocer algunos números comparativos en estudios mejor documentados, encontramos que en el carcinoma infiltrativo, por ejemplo, la adherencia a la piel (5) en una serie de 1.066 cánceres mamarios es de $43 \%$ La explicación de la piel de naranja es que la grasa comprendida entre masa tumoral y piel se atrofia; que las prolongaciones fibrosas subcutáneas se acortan y esclerosan y que por la invasión linfática subcutánea se produce el bloqueo de algunos pequeños vasos con el edema consiguiente.

Dolor.-En términos generales, en el carcinoma mamario el dolor es síntoma tardio, solo así se explica que en 423 casos de nuestro estudio, únicamente 97 acusaron dolor, o sea un 23.2\%. Es prudente advertir que la mayoría fueron casos quirúrgicos, no avanzados, porque de lo contrario el valor apreciativo del dolor carecería de importancia.

- Al revisar la variedad histológica del tumor en que se presentó el síntoma encontramos (cuadro número 46): 


\section{ELEMENTO DOLOR EN CANCERES MAMARIOS}

\begin{tabular}{lrcl}
\hline Variedad & Total & con dolor & Porcentaje \\
\hline Sarcoma & 5 & 2 & $40.0 \%$ \\
Paget & 4 & 1 & $25.0 \%$ \\
Adenocarcinoma & 287 & 70 & $24.0 \%$ \\
Esquirroso & 90 & 21 & $23.3 \%$ \\
Intracanalicular & 9 & 2 & $20.2 \%$ \\
Comedón & 10 & 1 & $10.0 \%$ \\
\hline
\end{tabular}

CUADRO NUMERO 46

En el adenocarcinoma infiltrativo, lo mismo que en la enfermedad de Paget y en la variedad esquirro, prácticamente el porcentaje es igual; en los sarcomas marca el máximo, con 40\%; en cambio, en el tipo comedón solo da el $10 \%$.

Supuración por el pezón.-Se trata de un síntoma de gran importancia por la preocupación de la paciente y las vacilaciones del médico ante el diagnóstico.

Afortunadamente la supuración por el pezón es escasa en el carcinoma. En este trabajo, como se puede apreciar en el cuaçro, se encontró el $2.7 \%$ en el adenocarcinoma infiltrảtivo en forma de líquido seroso; y el 1.3\% francamente purulento. En el carcinoma esquirro, el número fue $2.2 \%$ (líquido seroso) (cuaçro número 47 ).

SUPURACION POR EL PEZON

\begin{tabular}{|c|c|c|c|c|c|c|c|}
\hline \multicolumn{4}{|c|}{ Adenocarcinoma } & \multicolumn{4}{|c|}{ Esquirroso } \\
\hline Sangre & & 6 & $(6.6 \%)$ & Sangre & & 16 & $(5.4 \%)$ \\
\hline $\begin{array}{l}\text { Líquido } \\
\text { seroso }\end{array}$ & & 2 & $(2.2 \%)$ & $\begin{array}{l}\text { Líquido } \\
\text { serosó }\end{array}$ & & 8 & $(2.7 \%)$ \\
\hline Pus & & 0 & & Pus & & 4 & $(1.3 \%)$ \\
\hline & Total & 8 & & & Total & 28 & \\
\hline
\end{tabular}

CUADRO NUMERO 47

En una serie americana de 2.300 casos (6), el porcentaje fue ce $1.96 \%$ para las diversas formas de cáncer mamario, y en camkio, en conductos dilatados debajo del pezón, fue $32.0 \%$; igualmente se puede encontrar la supuración por el pezón en algunos casos de displasia mamaria, enfermedad quística, menopausia, adenosis, etc. Es, pues, más frecuente en patología mamaria con afecciones benignas que en el cáncer. 
Sangre por el pezón.-Síntoma importante en cancerología de la mama, aunque no es patognomónica.

Nosotros encontramos en el adenocarcinoma mamario sin descriminación por variedades histológicas el $12 \%$ en promedio. En una serie de 2.490 casos de cáncer, estudiada bajo este aspecto, se encuentran los siguientes porcentajes: cáncer infiltrativo c esquirroso, 2\%; cáncer papilar, $10 \%$; comedón, 25.4\%; canalicular el promedio fue de $4.1 \%$, inferior al nuestro.

Como contraste, encontramos en la misma serie americana. en un total de 2.917 casos de afecciones benignas de la mama, 185 con pezón sangrante, lo que da un porcentaje de $6.2 \%$, mayor aún que en los casos de carcinoma (4.1\%).

Hay que ser muy prudente en la apreciación de este sintoma para evitar determinaciones radicales equivocadas.

Cánceres ulcerados.--Al verificar la minuta encontramos 49 casos ulcerados $(11.6 \%)$.

Las variedades ulceradas se pueden apreciar en el siguiente cuadro (cuadro' número 48 ):

CANCERES ULCERADOS $49 \%$

\begin{tabular}{lrcc}
\hline \multicolumn{1}{c}{ Variedad } & Totales & Ulcerados & Porcentaje \\
\hline Adenocarcinoma infiltrativo & 287 & 32 & $11 \%$ \\
Esquirroso & 90 & 14 & $15.5 \%$ \\
Paget & 4 & 2 & $50.0 \%$ \\
Intracanalicular & 9 & 1 & $11.0 \%$ \\
\hline
\end{tabular}

CUADRO NUMERO 48

Solo reseñamos los hallazgos de la revisión al hacer el estudio anatómico de las piezas extirpadas. El mayor porcentaje correspondió al Paget $(50 \%$ ) y el mínimo (11\%) a la forma infiltrante del adenocarcinoma. Aproximadamente en un 50\% más, se ulcera el carcinoma esquirro que el infiltrante simple. La ulceración es siempre una complicación tardía, cuando la enfermedad lleva un promedio de $2 \frac{1}{2}$ años. A medida que avanza el tiempo, hasta llegar a las formas en coraza, el porcentaje es aún más alto. Estos casos finales son inoperables y no quedan incluídos en nuestra serie. Las entidades benignas, en términos generales, no se ulceran, a pesar de que el fibroadenoma puede hacerlo en un $\mathbf{0 . 6 5 \%}$ cuando es de gran tamaño. 


\section{Diagnóstico}

La importancia del diagnóstico precoz es aquí tan importante como en el carcinoma del útero o en el gástrico. Cada semana perdida ha sido estimada como un $4 \%$ menos en probabilidades de curación. El somero análisis que precede nos muestra la imposibilidad de diagnóstico correcto, en ausencia de biopsia, para lesiones cancerosas incipientes.

Los medios de examen de que disponemos son excelentes pe-; ro no dan siempre certeza. Vamos a enumerarlos brevemente; para mayor claridad:

19 Historia general de la paciente.

20 Historia especial concreta de los accidentes fisiológicos (partos, mastalgias menstruales y lactancia), etc., los patológicos como abscesos, mastitis, galactocele, "traumatismos, etc.

$3^{\text {o }}$ Precisión del tiempo corrido desde el primer hallazgo del tumor, supuración, hemorragia, etc.

4 \% Crecimiento lento o rápido del tumor.

50 Inspección amplia de los senos con levantamiento de brazos, para precisar deformidad, tumor, alteraciones de la piel (piel de naranja), dermatosis, eczemas, circulación normal visible, protusión o retracción del pezón, probabilidades de metástasis cutáneas, movilidad natural de los senos con los movimientos, tumor, aberrante, hoyuelos adherenciales, edema inflamatorio. adenopatías axilares o supraclaviculares, ulceración, hemorragia o supuración del pezón.

6 Palpación cuidadosa con las manos en posición de tocar piano, y ayudándose con la palma de las manos, suavemente, para localizar el tumor, la movilidad de la glándula mamaria o su estado adherencial a piel o planos profundos incluyendo parrilla costal. Igualmente se puede con la palpación hacer la localización de tumor en los cuatro cuadrantes (2 superiores y 2 inferiores) o en la zona central mamelonar. La palpación nos da luz. además, acerca de la forma, consistencia, contornos definidos o no, sensación especial propia de los quistes, o en remedo de paquete de lombrices, renitencia, prolongaciones fibrosas. Nos damos cuenta por último de las adenopatías en las zonas principales, con sus detalles respectivos.

79 La transiluminación ha sido un recurso de diagnóstico que puede ser útil en algunos casos. Solo se requiere cuarto oscuro 
y un dispositivo sencillo como una lámpara eléctrica de mano, por ejemplo, o lámpara camerón que es lo que nosotros empleamos corrientemente. Es preferible hacerlo de abajo hacia arriba y no lateralmente. Otra condición es la escogencia de los casos. porque en senos aplanados, o cuando el tumor está en la parte superior de la mama o adherido al tórax, la transiluminación no está indicada. La transiluminación nos puede informar acerca de la opacidad o de la transparencia del tumor. En términos generales el tejida adiposo es transparente, y el glandular lo es menos. Los quistes son transparentes, lo mismo que los pequeños tumores de menos de 2 centímetros. En cambio el carcinoma, hematomas y colecciones purulentas son opacas. En el carcinoma, nuestro tema, la opacidad y falta de contornos nítidos son la regla.

\section{Rayos X}

Se trata de un nuevo recurso todavía en trance experimental, tendiente a facilitar el diagnóstico de las neoformaciones mamarias. En reciente estudio de Gross y Sigrist (8), se muestra la bondad del método, con la presentación de buen número de radiografías de mama normal y patológica, que son probatorias de Ia eficacia alcanzada con los rayos $\mathrm{X}$ en los casos confusos de tumores del seno. En verdad la práctica de esta clase de radiografías y su correcta interpretación no es fácil, quizá por falta todavía de experiencia al respecto. Hay dos métodos principa'es para tomar las radiografías del seno: el directo y el del medio de contraste. En el directo, sin preparación especial de la enferma, sin el menor peligro, y que comúnmente es aceptado de buena voluntad, se toman dos radiografias en el sentido cráneopodál y otra de perfil. Para obtener buenas imágenes es conveniente un voltaje bajo, entre 25 a $40 \mathrm{Kvs.,} \mathrm{según} \mathrm{el} \mathrm{espesor} \mathrm{de}$ la mama, tratando de evitar el velo de difusión por medio de una compresión adecuada. La cráneo-podal se toma en posición ce pies, y la de perfil en decúbito dorsal o sentada con los brazos en alto y manos sobre la cabeza. Tiene la ventaja de que sé pueden repetir las-radiografías, y aún seguir el curso de las congestiones fisiológicas que acompañan la menstruación. La técnica es muy sencilla, más no lo es su buena interpretación, porque eș necesaria una experiencia comparativa obtenida por control cuidadoso de los casos intervenidos, para un buen diagnóstico. En algunos casos revela tumores pequeños que la palpación y la transiluminación no lo habian hecho. 
Las galactoforografias con medio de contraste, son aún más informativas y precisas. Tienen su indicación especial en los casos de supuración por el pezón o pérdidas sanguíneas, y su técnica es un poco más laboriosa: como medio de contraste se emplea el diiodone, sustancia soluble en agua, superior por consiguiente al lipiodol, y que requiere para ser inyectado la dilatación de los conductos galactóforos, a semejanza de lo que se hace con el canal lacrimal. No es dolorosa la inyección y al cabo de una hora, con un masaje suave se logra la eliminación del producto opaco. Es inútil insistir sobre la eficiencia del método en casos, v. gr.: de papilomas intracanaliculares. Su uso es restringido y sus indicaciones limitadas.

La esencia de las mamografías reside en el hecho de que los tumores benignos y las masas quísticas se ven con sus contornos definidos, móviles, sin adherencias, en tanto que los cánceres dan imágenes en forma de araña o estelares, adherentes e infiltrativos.

Consideramos de importancia iniciar labores en este nuevo campo de investigación, que promete ser un eslabón más en la difícil cadena del diagnóstico.

Biopsia.-Se conocen 2 procedimientos para la biopsia de las lesiones scspechosas de malignidad: la biopsia por aspiración y la quirúrgica. La primera tiene como indicación aquellos casos ce tumores avanzados clínicamente malignos, en los cuales la extirpación quirúrgica está contraindicada, y solo sería posible la irradiación, se utiliza el trócar de VIM Biopey Needle $\left({ }^{*}\right)$, que es el mismo dispositivo que se emplea para las biopsias de hígado.

En cambio la biopsia quirúrgica es el arma máxima y única capacitada para hacer el diagnóstico definitivo del carcinoma ciel seno. Lo más usado es hacer la extirpación del tumor cuando ul tamaño no sobrepasa las 5 centímetros, y practicar biopsia por congelación, que se lleva por todo unos 5 minutos. En el caso ce informe positivo, se coloca una compresa mojada en una sosución de cloruro de zinc al $50 \%$, y se procede a la mastectomía.

Muchos se preguntan acerca de los inconvenientes o peligros de diseminación por las maniobras de la biopsia. La respuesta hoy es que es preferible a todo trance un diagnóstico correcto, y éste solo se consigue por la biopsia quirúrgica, si es posible con è̀ bisturí eléctrico.

(*) Mc Gregor Instrument Co. Medham. Mass U. S. A. 


\section{Diagnóstico o presunción clínica squivocados}

Con diagnóstico clínico de otras entidades de patología de mama se hizo la mastectomía en 29 casos $(6.8 \%)$; y al hacer el estudio histopatológico se halló cáncer (cuadro nụmero 49).

\section{PRESUNCION CLINICA EQUIVOCADA}

\begin{tabular}{ll}
\hline Fibroadenoma & 7 \\
Mastitis Crónica & 5 \\
Mastitis Quística & 4 \\
Fibroma & 3 \\
Quiste del Seno & 3 \\
Sarcoma & 2 \\
Cisto Sarcoma Filoides & 1 \\
Micosis & 1 \\
Linfoma & 1 \\
Dermitis Crónica & 1 \\
Fibromioma & 1 \\
& Total \\
\hline
\end{tabular}

\section{CUADRO NUMERO 49}

Está consignado en los estudios anteriores de lesiones benignas de la mama.

Tiempo de evolución.-Con tiempo de evolución consignado en los protocolos del Instituto de Anatomía Patológica, hallamos 309 casos $(73 \%)$; en $114(27 \%)$, el dato no existía. En el cuadro siguiente podemos apreciar el pormenor (cuadro número 50 ).

\section{EVOLUCION}

\begin{tabular}{lcr}
\hline Tiempo & Número & Porcentaje \\
1 a 3 meses & 42 & $13.6 \%$ \\
4 a 6 meses & 68 & $22.0 \%$ \\
7 a 8 meses & 26 & $8.4 \%$ \\
9 a 12 meses & 76 & $24.6 \%$ \\
13 a 15 meses & 9 & $2.9 \%$ \\
16 a 18 meses & 10 & $3.2 \%$ \\
19 a 24 meses & 23 & $7.4 \%$ \\
2 a 4 años & 29 & $9.4 \%$ \\
6 a 15 años & 26 & $8.4 \%$ \\
Total & 309 & $73 \%$ \\
Sin evolución anotada & 114 & $27 \%$ \\
\hline
\end{tabular}


En primer término vemos que la cuarta parte (24.6\%) consultaron entre 9 y 12 meses de evolución; y un número muy vecino $(22 \%)$ entre 4 y 6 meses. Solamente un $13.6 \%$ acudieron a tratamiento en el curso de los tres meses iniciales de la enfermedad. La última columna muestra evoluciones entre 6 y 15 años que a primera vista parece reñida con la verdad, pero es seguro que se trataba de afecciones benignas que con el andar del tiempo se degeneraron.

\section{Tratamiento}

Se conocen 2 procedimientos principales para el tratamiento curativo del carcinoma del seno: cirugia e irradiaciones. Además, hay terapias paliativas para aliviar síntomas y complicaciones, tanto en aquellos casos llegados tardiamente a consulta, como en otros donde el tratamiento no alcanzó la curación ${ }^{4}$ de la paciente.

Cirugía.-La mastectomía radical, operación ideada por Halsted y Meyer, tenía como fundamente único la extirpación, lo más amplia posible, del tumor y sus metastasis axllares. En aquella época se desconocía la teoría de Handley sobre la permeación linfática, como patogenia de las linfitis y adenitis cancerosas, pero el buen sentido clínico de aquellos cirujanos fue lo suficientemente ágil para la creación de una intervención que ha resistido el control del tiempo y lăs controversias de la ciencia.

La cirugia del cáncer constituye una especialidad dentro de la misma cirugia, porque aparte de todas las normas generales. anatómicas y fisiológicas indispensables, el cirujano tiene la obligación perentoria de hacer del tumor una extirpación de tal naturaleza, que no deje una sola célula cancerosa en el organismo del paciente: hacer cirugía mutilante a medias es de gran responsabilidad ante Dios y ante la sociedad.

Los detalles de la técnica de la mastectomia radical están publicados en todos los textos de práctica quirúrgica y no es del caso incluírlos en el presente trabajo.

El criterio de operabilidad es un poco elástico. Nos puede servir de guía el grado de extensión del tumor, de acuerdo con la clasificación de Steinthal que la consideramos de gran útilidad. En el grado primero, el tumor está limitado a la mama, conserva su movilidad absoluta y hay ausencia de ganglios axilares comprometidos; en el grado segunḍo, la mayor parte de la glándula está invadida, hay adherencias a la piel y los gánglios axi- 
lares se encuentran afectados; y en el grado tercero, la glándula está totalmente invadida, la piel y tejidos submamarios están adheridos formando un solo bloque, en veces hay ulceraciones de la piel, se palpan además, frecuentemente, los gánglios axilares y supraclaviculares infartados y puede encontrarse en muchos casos la presencia de metástaisis óseas o viscerales. Dentro de esta clasificación, los casos de grado primero son esencialmente quirúrgicos, y son los que arrojan el más alto grado de curabilidad, tanto de 5 años, como la curación por tiempo indefinido. Las diversas estadísticas concuerdan en un promedio de $2 / 3$ partes de supervivencia para cualquiera que sea la variedad histológica del tumor. Infortunadamente, solo la cuarta parté de las pacientes consultan cuando la enfermedad se halla dentro cel grado primero.

En los casos de segundo grado, la cirugía conserva aún sus derechos, pero con probabilidades menores de curación, y con el auxilio necesario de los rayos $\mathrm{X}$. El porcentaje de curación desciende a un promedio de $25 \%$, menos en lo referente a la supervivencia de los 5 años.

En cuanto al grado tercero, la cirugia propiamente dicha, entendiendo por tal la mastectomía radical, se puede considerar hoy día contraindicada, para confiar el tratamiento a otros procedimientos, toda vez que el-resultado final de 1 os 5 años, únicamente oscila alrededor de $5 \%$.(cirugia y radioterapia), en tanto que la irradiación sin cirugia puede apuntarse un $10 \%$ en igualdad de condiciones. Seria exponer entonces la paciente a un tratamiento quirúrgico inútil e inconveniente.

Riesgo operatorio. - La mortalidad inmediata es baja, a condición de buena preparación pre-operatoria y una correcta técnica en el arte quirúrgico, incluyendo naturalmente la buena anestesia y la prevención del shock. Reunidas todas èstas condiciones, se ha logrado llegar a un promedio de $1 \%$ en los mejores centros especializados en esta clase de cirugia.

En los casos a que se refiere este trabajo, la mortalidad operatoria fue de $0.24 \%$.

La operación ejecutada fue siempre la de Halsted, con ligeras modificaciones en lo referente a la incisión y al cierre, porque en algunas ocasiones hubo necesidad de practicar técnicas especiales, acudiendo a plastias de pared abdominal en lugar de injerto de piel y que no detallamos por las razones anotadas. 
Radioterapia del carcinoma mamario.--Para la irradiación del cáncer del seno se emplea preferencialmente entre nosotros los rayos $\mathrm{X}$. Con la misma lógica que empleamos para excluir de esta comunicación las técnicas de la mastectomia, nos abstenemos igualmente de abordar las muy especializadas de las irradiaciones, bien sean las referentes a los rayos $\mathrm{X}$, al radium, o de isótopos radioactivos, las radiaciones nacientes producidas en ciclotrom de Lauvrence, o las de Betatron.

En el grupo. muy numeroso por cierto (40\%), de los carciromas de grado tercero, la mejor conducta terapéutica es la irraaiación.

A medida que la cirugia restringe su campo de acción, al seleccionar sus casos con el moderno criterio de operabilidad, la actinoterapia en cambio se extiende más y más, porque es el único recurso que le queda a la enferma. El carcinoma mamario es cie una sensibilidad relativa a la roëntgenterapia por su naturaleza misma glandular, a pesar de que la práctica cotidiana demuestra con hechos palpables que la mayor parte de los cánceres mamarios disminuyen de tamaño con las irradiaciones, recuperan la movilidad perdida y hay regresión general de la enfermedad, al menos temporalmente.

Así se ha alcanzado colocar en condiciones quirúrgicas algunas pacientes inoperables, aunque el pronóstico continue sombrio debido a las metástasis óseas o viscerales. Es, pues, la irradiación la mejor solución terapéutica para los carcinomas avanzados de grado tercero.

Cirugia y Rayos $X$.-La asociación de la cirugia con la radioterapia es lo que comúnmente se llama terapéutica combinada. Puede hacerse en dos formas: pre-operatoria y post-operatoria. La idea de la irradiación post-operatoria nació de la inseguridad que daba la cirugía sola en los buenos casos clínicos (grado primero), cuando la mastectomía radical alcanzaba únicamente un porcentaje de curación de 5 años, en 65 a $70 \%$, hecha en las mejores condiciones. Efectivamente, se registró una ligera alza en el número de curaciones, más o menos un $2 \%$, pero es cie justicia agregar que cada servicio registra su estadistica propia, y que hay algunas clínicas que anotan hasta un 4 y $5 \%$ de margen de seguridad con la radioterapia post-operatoria.

En el afán de mejorar aún más el indice de curabilidad, se ideó la irradiación pre-operatoria, con la cual se buscaba la reducción en tamaño del tumor y una mejor movilidad. No obstan- 
te, se le acusa de ser empleada sin previa biopsia y por consiguiente sin diagnóstico positivo de carcinoma, ya que dejamos $\epsilon$ stablecido que la biopsia positiva debe ser inmediatamente sezguida de la mastectomía. Queda el recurso de una biopsia por aspiración, y si ella confirma el diagnóstico de un carcinoma altamente anaplásico, es aconsejable la irradiación. En el carcinoma gelatinoso y en el Paget propagado a la glándula está desaconsejada la irradiación previa.

En cuanto a la radioterapia post-operatoria, conviene advertır que no parece una medida catalogable de rutina como actualmente se ha hecho ley. Tiene sus indicaciones precisas cuando el. tumor es difuso y de tamaño aproximado de 5 centimetros, y muy especialmente cuando los gánglios axilares están afectados. También en el curso mismo de la intervención puede ser sorprencido el cirujano con el hallazgo de un tumor con extensión e invasión de los tejidos mayor de lo esperado, caso en el cual se justifica la radioterapia complementaria. En cambio, en los cánceres de grado I (uno), correctamente intervenidos, no es aconsejable la irradiación de rutina, entre otras razones porque convendria aplazarse para en caso de alguna recidiva ya que si se irradia previamente, nos quedamos sin armas para el combate final. Además, no es completamente inocua para el organismo $\in \mathrm{n}$ general, y para el tórax en particular (a pesar de los avances (e la técnica) la irradiación de rutina. Hay estadísticas publicadas en el estudio de que para los cánceres mamarios número 1. ia radioterapia en poco o nada mejora la supervivencia de los 5 años. Es entendido que solo tratamos de la radioterapia de rutina. sin tratar de descalificar una medida terapéutica universalmen. te reconocida y que nosotros humildemente aceptamos como de: gran valor.

\section{Tratamiento de metastasis tordías}

El tratamiento de las metástasis del cáncer del seno tiene necesariamente que ser variado, porque está subordinado al sitio donde se presenten.

Cuando son metástasis ganglionares recidivantes en axila y región clavicular, en general, son tributarias de radioterapia; e igual suerte deben correr en caso de localización mediastinal o en paredes del tórax. En las metástasis óseas, bien sea en columna vertebral, huesos craneanos o pélvicos y extremidades superiores del fémur y húmero, es necesario un tratamiento especial. 
En pacientes que estén todavía bajo el influjo hormonal estrogénico, deben ser operadas, para practicarles la castración quirúrgica, de preferencia a la castración roëntgeniana. La quirúrgica despeja el problema hormonal de inmediato. en tanto que Ios rayos $\mathrm{X}$ lo hacen lentamente, en el cursc de varias semanas, $y$ en estos casos angustiados, el factor tiempo es de una importancia capital, aparte de que los rayos $\mathrm{X}$ actúan especialmente en los folículos de Graaf, maduros o en maduración, lo mismo que sobre las células de la granulosa y tecales, y menos intensamente sobre el estroma y la masa de folículos semimadurantes, cie tal naturaleza que a pesar de la irradiación siguen aún produciendo estrógenos por algún tiempo. En nuestras pacientes particulares, no hospitalarias, hemos practicado la castración quirúrgica cuando el extendido vaginal nos muestra un hiperestrogenismo franco. En las menospáusicas, o cuando las pacientes están aún en actividad genital.

En los últimos tiempos se ha acudido a medidas extremas para alcanzar la total supresión de estrógenos en estas enfermas, y para éstos se propuso además de la castración la extirpación ce ambas glándulas suprarrenales productoras de estrógenos. Años más tarde se preconizó la hipofisectomía como medida, además es indispensable la hormonoterapia cruzada, a fin de dar a la enferma las mayores posibilidades de supervivencia. Esto bajo cl punto de vista hormonal, porque conviene también agregar ia terapia por los rayos $\mathrm{X}$, con técnicas precisas, a nivel del sitio a.fectado.

\section{Sumario}

Se estudian 1.181 casos de patología de la mama, vistos en el Instituto de Anatomía Patológica de la Facultad de Medicina be la Universidad de Antioquia en el curso de 13 años. En primer término se aborda el estudio de las lesiones inflamatorias, mastitis agudas, subagudas y crónicas, con cuadros estadísticos y al\&unas microfotografías. En segundo Iugar se revisan los tumores kenignos de la mama, señalando su frecuencia, sintomatológica y tratamiento a que fueron sometidos y en tercer lugar se hace la revisión de 423 casos de cánceres de mama estudiados en el mismo Instituto, en un lapso de marzo de 1944 a junio de 1947, y se estudia la frecuencia entre nosotros, la edad de aparición, alguy localización del tumor, las metástasis ganglionares y visceraros factores etiológicos, las diversas variedades histopatológicas les, lo mismo que la patogenia de algunas en particular, como. 
por ejemplo, las de huesos craneanos, cuerpos vertebrales, huesos de la pelvis y extremidades superiores del fémur y húmero. Se hace un comentario sobre 6 autopsias de muertes ocurridas en el mismo lapso por cáncer de mama, con los hallazgos correspondientes.

Se hace una revisión general acerca de algunos síntomas principales, como la retracción y protusión del pezón, la llamada piel de naranja, la secrección o supuración por el pezón, la hemorragia, la ulceración de la piel, etc., para el análisis de su verdadero valor clínico y comparación con su frecuencia en otras mastopatías bengnas.

Se mencionan los medios de diagnóstico principales. como la palpación, inspección, transiluminación, rayos $\mathrm{x}$ y la biopsia, tanto por aspiración como la quirúrgica, sea por congelación o por el estudio completo del tumor.

Se hace un estudio comparativo acerca de los tratamientos principales del carcinoma del seno, en sus diversos grados, según la clasificación de Steinthal, con el fin de orientar la conducta terapéutica más aconsejable.

$Y$ por último, se hace mención del tratamiento de alguunas metástasis, especialmente las óseas, por medios modernos hoy establecidos en los centros científicos de mayor renombre.

\section{Conclusiones}

1a. Se hace indispensable la biopsia quirúrgica o por congelación, antes de practicar la mastectomía, para evitar operaciones innecesarias, como en casos de mastitis y tumores benignos.

$2^{\text {a }}$ El cáncer del seno es menos frecuente entre nosotros que en algunos países de gran civilización, como por ejemplo en los Estados Unidos de Norteamérica.

3 a El carcinoma de mama puede presentarse después de la segunda década de la vida en adelante, siendo la edad de mayor frecuencia la correspondiente a la quinta década (entre los 40 y 50 años).

$4^{\text {a }}$ El factor hormonal, especialmente el hiperestrogenismo, parece jugar un papel importante en la patología del cáncer, como lo prueba la regresión de las metástasis óseas con la supresión parcial o total de los estrógenos.

5a $\mathrm{El}$ adenocarcinoma infiltrativo y su variedad esquirrosa representa, más o menos, el $90 \%$ de todos los cánceres de mama.

6a Las adherencias del tumor a la piel estableciendo la llamada piel de cerdo o de naranja, no son exclusivamente propias 
तel tumor maligno. Igual afirmación puede hacerse con respecto a la retracción o protusión del pezón, a la supuración o hemorragia por el mismo, toda vez que también pueden encontrarse estos sintomas en lesiones no cancerosas de la mama. Es necesario complementar lo dicho con la afirmación enfática de que la presencia de cualquiera de estas condiciones clínicas, es de gran valor en el diagnóstico del cáncer del seno.

7ạ Las metástasís..cancerosas van apareciendo a medida que el curso de la enfermedad avanza, cualquiera que sea el tamaño de la lesión inicial.

8a El diagnóstico correcto del cáncer del seno es siempre ditícil en el curso de los primeros meses de la enfermedad, y entre nosotros solo la biopsia da la seguridad absoluta de diagnóstico positivo.

9a Los carcinomas mamarios de grado primero correctamente diagnosticados son exclusivos de la cirugia. No justifican racioterapia, $\mathrm{y}$ es aconsejable aplazar los rayos $\mathrm{X}$ para el caso infortunado de reproducción, como medida de último recurso.

Los cánceres de grado tercero deben ser irradiados como unica medida. La cirugia no se justifica. En cuanto a los grados segundos, deben operarse e irradiarse, bien sea con irradiación previa, de acuerdo con el caso clínico, o radioterapia post-operatoria.

10. Las pacientes con metástasis óseas, antes de la menopausia, o primeros años después de ella, deben ser intervenidas para ovariectomía bilateral, y tratamiento hormonal cruzado complementario.

\section{BIBLIOGRAFIA}

1. C. E. GESCHICKTER,-Enfermedades de la mama. 1957. Página 415.

2. 1-a. Página 428.

3. 1-b. Página 465.

4. 1-c. Página 466.

5. 1-d. Página 479.

6. 1-e. Página 343.

7. SAILER S.-Sarcoma of the Breast. Amer Jour Cáncer 31: 183, 1937.

8. JEAN DALSACE R. SIGRIST.-Página 167. J. García Calveron. Gynecologie Rạdiologique et Radiographic đu Sein Ch. Gross. 